\title{
Rat PRDM9 shapes recombination landscapes, duration of meiosis, gametogenesis, and age of fertility
}

Ondrej Mihola', Vladimir Landa ${ }^{2}$, Florencia Pratto ${ }^{3}$, Kevin Brick$^{3}$, Tatyana Kobets ${ }^{1}$, Fitore Kusari ${ }^{1}$, Srdjan Gasic ${ }^{1}$, Fatima Smagulova ${ }^{4,5}$, Corinne Grey ${ }^{6}$, Petr Flachs ${ }^{1,7}$, Vaclav Gergelits ${ }^{8}$, Karel Tresnak ${ }^{1}$, Jan Silhavy ${ }^{2}$, Petr Mlejnek ${ }^{2}$, R. Daniel Camerini-Otero ${ }^{3}$, Michal Pravenec ${ }^{2}$, Galina V. Petukhova ${ }^{4}$ and Zdenek Trachtulec ${ }^{1 *}$ (D)

\begin{abstract}
Background: Vertebrate meiotic recombination events are concentrated in regions (hotspots) that display open chromatin marks, such as trimethylation of lysines 4 and 36 of histone 3 (H3K4me3 and H3K36me3). Mouse and human PRDM9 proteins catalyze H3K4me3 and H3K36me3 and determine hotspot positions, whereas other vertebrates lacking PRDM9 recombine in regions with chromatin already opened for another function, such as gene promoters. While these other vertebrate species lacking PRDM9 remain fertile, inactivation of the mouse Prdm9 gene, which shifts the hotspots to the functional regions (including promoters), typically causes gross fertility reduction; and the reasons for these species differences are not clear.

Results: We introduced Prdm9 deletions into the Rattus norvegicus genome and generated the first rat genomewide maps of recombination-initiating double-strand break hotspots. Rat strains carrying the same wild-type Prdm9 allele shared $88 \%$ hotspots but strains with different Prdm9 alleles only 3\%. After Prdm9 deletion, rat hotspots relocated to functional regions, about $40 \%$ to positions corresponding to Prdm9-independent mouse hotspots, including promoters. Despite the hotspot relocation and decreased fertility, Prdm9-deficient rats of the SHR/OlalpcV strain produced healthy offspring. The percentage of normal pachytene spermatocytes in SHR-Prdm9 mutants was almost double than in the PWD male mouse oligospermic sterile mutants. We previously found a correlation between the crossover rate and sperm presence in mouse Prdm9 mutants. The crossover rate of SHR is more similar to sperm-carrying mutant mice, but it did not fully explain the fertility of the SHR mutants. Besides mild meiotic arrests at rat tubular stages IV (mid-pachytene) and XIV (metaphase), we also detected postmeiotic apoptosis of round spermatids. We found delayed meiosis and age-dependent fertility in both sexes of the SHR mutants.

(Continued on next page)
\end{abstract}

* Correspondence: Zdenek.Trachtulec@img.cas.cz

'Laboratory of Germ Cell Development, Division BIOCEV, Institute of

Molecular Genetics of the Czech Academy of Sciences, 14220 Prague, Czech

Republic

Full list of author information is available at the end of the article

\section{$\triangle B M C$}

(c) The Author(s). 2021 Open Access This article is licensed under a Creative Commons Attribution 4.0 International License, which permits use, sharing, adaptation, distribution and reproduction in any medium or format, as long as you give appropriate credit to the original author(s) and the source, provide a link to the Creative Commons licence, and indicate if changes were made. The images or other third party material in this article are included in the article's Creative Commons licence, unless indicated otherwise in a credit line to the material. If material is not included in the article's Creative Commons licence and your intended use is not permitted by statutory regulation or exceeds the permitted use, you will need to obtain permission directly from the copyright holder. To view a copy of this licence, visit http://creativecommons.org/licenses/by/4.0/ The Creative Commons Public Domain Dedication waiver (http://creativecommons.org/publicdomain/zero/1.0/) applies to the data made available in this article, unless otherwise stated in a credit line to the data. 
(Continued from previous page)

Conclusions: We hypothesize that the relative increased fertility of rat versus mouse Prdm9 mutants could be ascribed to extended duration of meiotic prophase I. While rat PRDM9 shapes meiotic recombination landscapes, it is unnecessary for recombination. We suggest that PRDM9 has additional roles in spermatogenesis and speciation-spermatid development and reproductive age-that may help to explain male-specific hybrid sterility.

Keywords: Rattus norvegicus, Meiotic recombination, PRDM9, Fertility

\section{Background}

For sexual reproduction, animals generate haploid gametes via meiosis. To make these gametes unique, programmed double-strand DNA breaks (DSBs) are introduced and repaired by the recombination machinery using the homologous chromosomes as templates (reviewed in [1]). These meiotic DSBs are positioned by the histone-H3-lysine-4-trimethyl (H3K4me3) transferase PRDM9 in mice and men [2-5]. The mouse Prdm9 gene is one of the factors responsible for intersubspecific mouse F1 hybrid sterility [6-8] due to changed DNA-binding specificity [9]. The changes in DNA binding by new PRDM9 alleles generate new recombination initiation sites and thus resolve the so-called meiotic hotspot paradoxthe quick disappearance of the preferential DSB sites through their repair utilizing the homologous chromosome sequences, which do not contain the PRDM9binding motifs [10]. Deficiency for Prdm9 results in complete meiotic arrest in both sexes of the C57BL/6 J mouse (abbreviated as B6) [7, 11-13] and partial meiotic arrest in the male PWD/Ph mouse [14], accompanied by relocation of the DSBs into PRDM9-independent H3K4me3 sites (default sites) including gene promoters $[14,15]$. These results lead to the hypothesis that PRDM9 protects functional genomic regions from the damage made by the recombination machinery [15]. However, most of the recombination initiation DSB sites are located near gene promoters in fungi and vertebrates that carry no Prdm9 ortholog [16-18]. In addition, canids [19-22] and at least one human female [23] are fertile despite having a non-functional PRDM9-encoding gene. We therefore turned to another prominent rodent model, the rat, to evaluate the role(s) of Prdm9 in gamete development. Prdm9-deficient rats were produced and phenotyped along with their littermate controls and the first genomewide maps of the rat meiotic DSBs were generated. The DSBs in the Prdm9-deficient males of the SHR rat strain relocated into default H3K4me3 sites, many corresponding to DSB positions in Prdm9-deficient mice. However, unlike the B6 or PWD mice, some SHR rats of both sexes lacking the Prdm9 function produced offspring. Nevertheless, we found that PRDM9 affects the length of meiosis and age of fertility in both sexes, as well as oogenesis and spermiogenesis. We conclude that the rat can execute meiotic recombination in PRDM9-independent sites, rendering it a suitable model for human meiotic studies. Moreover, the postmeiotic effect of PRDM9 on spermatogenesis widens the possibilities for the mechanism of PRDM9 action in hybrid sterility.

\section{Results}

Generation of the Prdm9-deficient rats

Although some mammalian genomes carry multiple PRDM9-encoding genes, the rat genome was reported to contain only a single-copy $\operatorname{Prdm} 9$ gene [24]. To decipher the necessity of Prdm9 for rat fertility, we targeted this gene in the SHR/OlaIpcr strain (SHR; see Methods) in one of the exons encoding the PR/ SET domain. This domain catalyzes both H3K4 [12] and H3К36 trimethylation in human and mouse [25, 26]. The mRNAs of a programmed heterodimeric nuclease were injected into 234 fertilized ova (Table 1 ). Four animals carrying deletions of two, eight, 39, and 516 base pairs in size (bp) were generated; the two largest ones also affected one exon-intron boundary. To assess the effects of these deletions on Prdm9 mRNA, we performed reverse-transcribed (RT) PCR with primers from the exon sequences surrounding the deletions using testicular RNA. Sequencing of these RT-PCR products from testicular RNA revealed that the three shortest deletions resulted in the shifts of PRDM9 open reading frames, producing putative $\mathrm{PR} / \mathrm{SET}$ domain truncations and exclusion of the PRDM9 zinc-finger DNA-binding domain (Fig. 1). The mutant with the 516-bp deletion produced two new transcripts, one with a frame shift and one with

Table 1 Preparation of Prdm9 mutant SHR animals by mRNA injections

\begin{tabular}{llll}
\hline Experiment & $\mathbf{1}$ & $\mathbf{2}$ & Total \\
\hline mRNA concentration & $2 \mathrm{ng} / \mu \mathrm{l}$ & $5 \mathrm{ng} / \mu \mathrm{l}$ & Both \\
Injected zygotes & 121 & 113 & 234 \\
Transferred embryos 2c/1c* & $57 / 18$ & $62 / 21$ & $119 / 39$ \\
Female recipients & 6 & 7 & 13 \\
Pregnant recipients & 3 & 3 & 6 \\
Live progeny born & 15 & 8 & 23 \\
Mutants & 3 & 1 & 4 \\
\hline
\end{tabular}

*2-cell stage/1-cell stage transferred into recipients after $20 \mathrm{~h}$ of in vitro culture post injection 


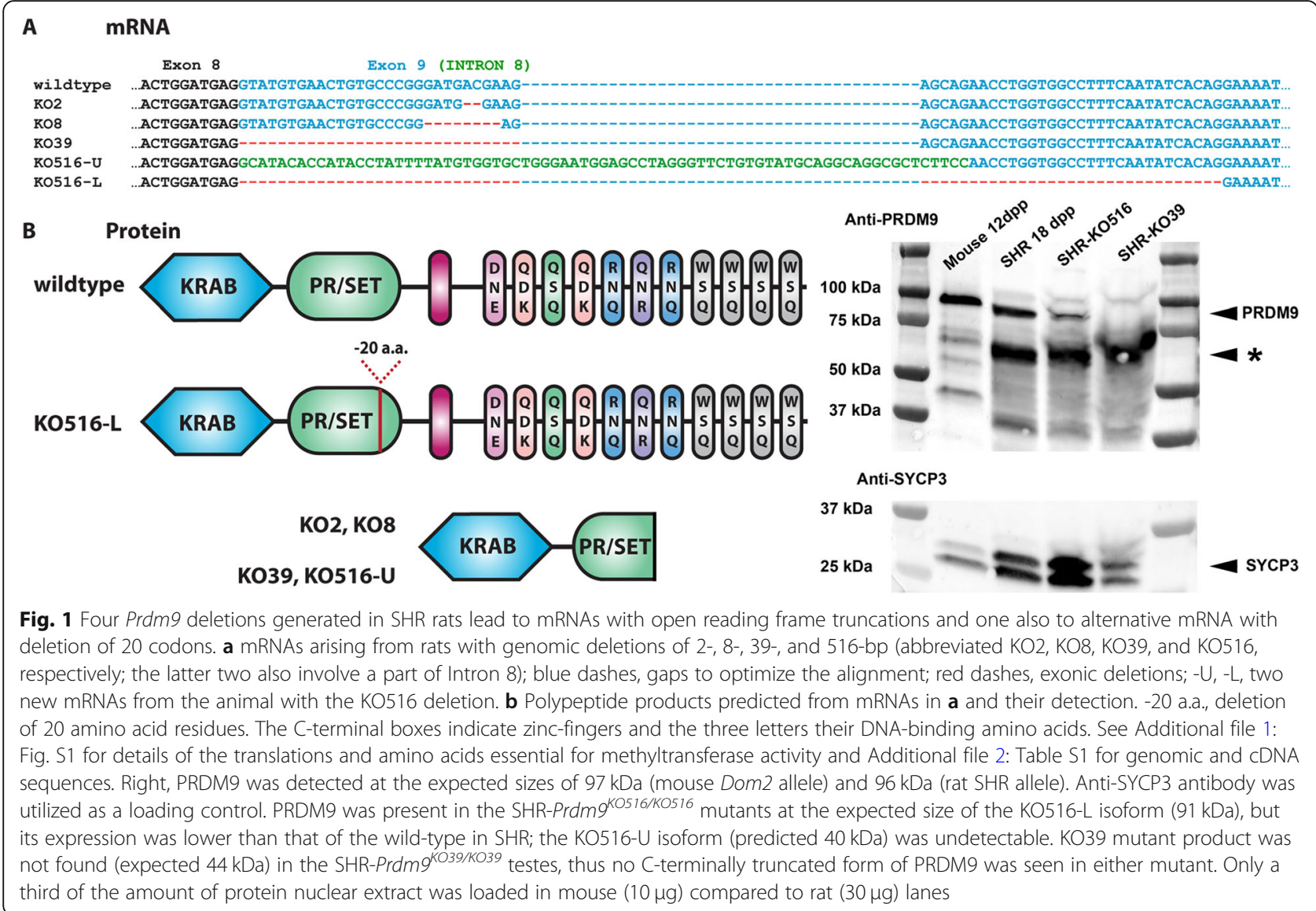

an internal deletion of 20 codons of the PR/SET catalytic domain that retained the PRDM9 zinc-fingerencoding exon in frame (Fig. 1, Additional file 1: Fig. S1). All deletions removed one or more amino acid residues important for the methyltransferase activity of PRDM9 ([27]; Additional file 1: Fig. S1). Rats genotyped homozygous for these mutations using genomic DNA were also homozygous when probed by RT-PCR using testicular mRNA, supporting whole genome sequence assembly data that suggested that $\operatorname{Prdm} 9$ is present in a single copy in the rat [24, 28]. Semiquantitative RT-PCR of testicular RNA revealed that males homozygous for the Prdm9 deletions of 2-, 8-, and 39-bp display similar mRNA levels as littermate controls and confirmed expression of the two new mRNA isoforms from the mutant with the 516-bp deletion (Additional file 1: Fig. S2).

To evaluate PRDM9 protein expression in wild-type and mutant testes, we performed Western blotting (Fig. 1b). PRDM9 was detected SHR testes at 18 days post partum (dpp), where most germ cells are pre/leptotene and zygotene spermatocytes (see below for details on 18-dpp testes). Neither PRDM9 protein nor its truncated form was found in 18-dpp SHR-Prdm9 $9^{K O 39 / K O 39}$ rat testes, suggesting that its frame-shifted mRNA is not translated or quickly degraded. PRDM9 was present in 18-dpp SHR-Prdm9 $9^{K O 516 / K O 516}$ rats at the size of $91 \mathrm{kDa}$ predicted from the mRNA with the internal deletion of 20 codons of the catalytic PR/SET domain, but not at the size of $40 \mathrm{kDa}$ expected from the alternatively spliced mRNA with the frame shift. However, the expression of the $91 \mathrm{kDa}$ product was lower than the expression of the wild-type PRDM9.

\section{Inactivation of rat Prdm9 is compatible with fertility in both sexes}

We next tested the fertility of the rats carrying the Prdm9 deletions. Twenty-one of 22 (95\%) of Prdm9-deficient and all 26 tested heterozygous males sired offspring. Heterozygous $\operatorname{Prdm} 9^{K O / w t}$ males that produced at least two litters $(n=26)$ sired $6.8 \pm 1.6$ (mean \pm standard deviation) of offspring per female per month, 32\% more compared to the Prdm9-deficient males with at least two litters $(n=15 ; 4.6 \pm 2.1 ; P=0.0009$; Welsch's $t$ test; Fig. 2f). The litter size itself also decreased in Prdm9-deficient males (Fig. 2e). Adult (71 to 98 days old) Prdm9-deficient males had relative testicular weight and sperm count reduced by about $40 \%$ compared to 


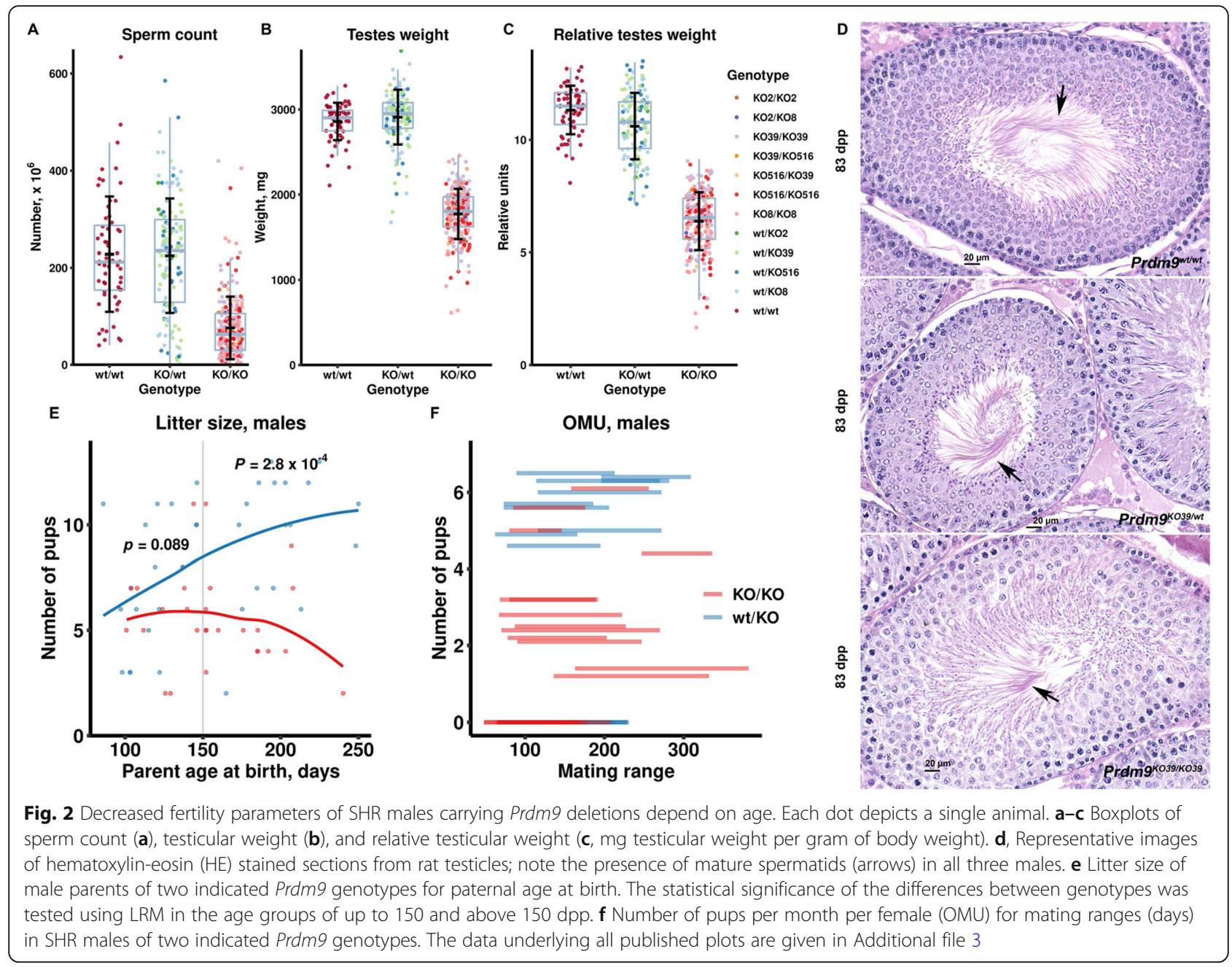

both heterozygote and wild-type rats $(P<0.0001$ each; linear regression model (LRM); Fig. 2a-c, Additional file 1: Fig. S3).

Prdm9-deficient adult females (69 to 373 days old) had decreased ovary weight and relative ovary weight compared to controls $(P<0.0001, \mathrm{LRM}$ accounting for age; Fig. 3a, b, Additional file 1: Fig. S3). Of 25 Prdm9-deficient females crossed for at least 2 months, 11 (44\%, carrying all four deletion types) produced offspring, while all 27 tested $\operatorname{Prdm} 9^{K O / w t}$ females yielded pups. Moreover, the litter size of the Prdm9deficient $\left(\operatorname{Prdm} 9^{K O / K O}\right)$ female parents $(5.4 \pm 1.7)$ was smaller than that of $\operatorname{Prdm} 9^{K O / w t}(8.3 \pm 1.6 ; P=0.0003$; Welsch's $t$ test; Fig. 3d). The pups generated by both the male and female $\operatorname{Prdm} 9^{K O / K O}$ rats were fertile and appeared normal. No offspring has been recovered when both mating partners were Prdm9-deficient (7 females, 2-month crosses). In summary, in contrast to B6 and PWD mice, both male and female SHR rats lacking PRDM9 function display only a partial reduction of fertility.

\section{Inactivation of rat Prdm9 induces four partial arrests of spermatogenesis}

To uncover the reasons for male fertility reduction, we performed immuno-, histo-, and cyto- chemistry of the germline. Within an adult rat testis, subsequent waves of spermatogenesis begin once every $\sim 12$ days $(8-9$ in the mouse) [29]; the entire rat spermatogenesis takes $\sim 52$ days. Premeiotic spermatogonia line the periphery of the seminiferous tubule, divide mitotically, and mature. The resulting primary spermatocytes proceed through meiotic prophase and two specialized divisions to yield spermatids, which differentiate into sperm until being released into the tubular lumen. Because a new spermatogenesis cycle begins before the previous cycles have ended, each tubule carries various germ cell types. As both the time between cycles and the duration of individual developmental stages are fixed, each rat tubule section can be classified into 14 types (12 in the mouse), referred to as stages I to XIV.

To identify the specific stages of the seminiferous tubules in the mutant testes affected by $\operatorname{Prdm} 9$ 


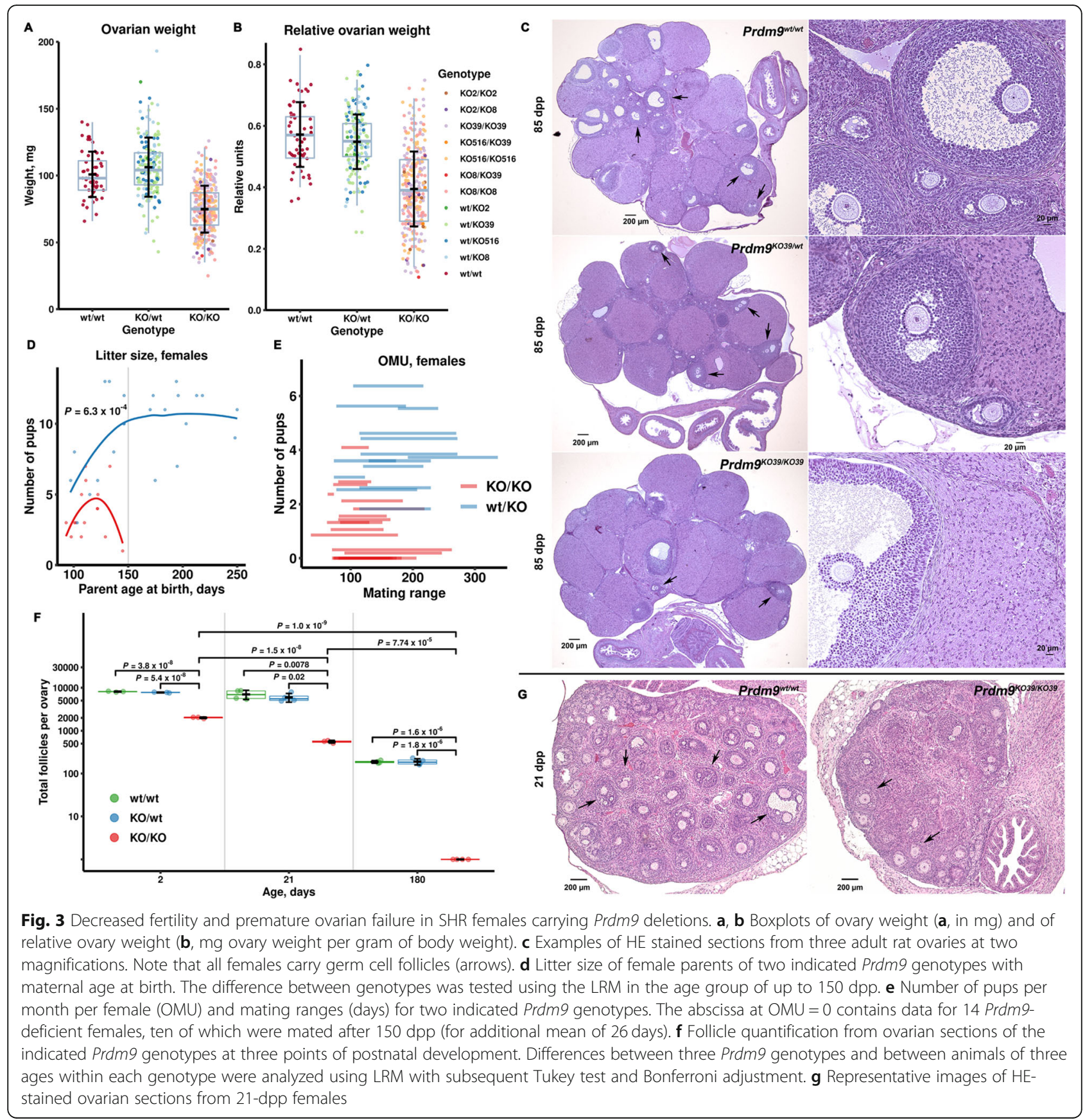

inactivation, we categorized and quantified cells in all 14 stages of rat tubules (over 60,000 cells) using sections from adult testes stained with periodic acid, Schiff, and hematoxylin (PAS-H, Fig. 4a and Fig. 5, statistics in Additional file 2: Table S2). Overall, all 14 tubule stages were readily identifiable and the counts of spermatogonia were similar in the mutant and control rat testes. However, the mutant tubules of all stages were more sparsely populated compared to controls (all 14 adjusted $P$ values below 0.036 ; LRM), mostly due to lower counts of round and elongated spermatids (all $22 \quad P<0.037$ ).
These decreased numbers of spermatids could occur either solely due to partial meiotic arrest(s) or postmeiotic arrest(s) or both. To resolve these three possibilities, we compared abnormal cell counts. We found elevated counts of abnormal (halo [30], joint and degraded [31]) round spermatids in mutant stages IV (summary $P=$ $0.027)$ and V $(P=0.028)$ compared to wild-type controls, which supports the contribution of the postmeiotic arrests (Fig. 6a). Moreover, we detected an increased number of defective mid-pachytene spermatocytes in stage IV $(P=0.022)$ and of degenerated metaphase 


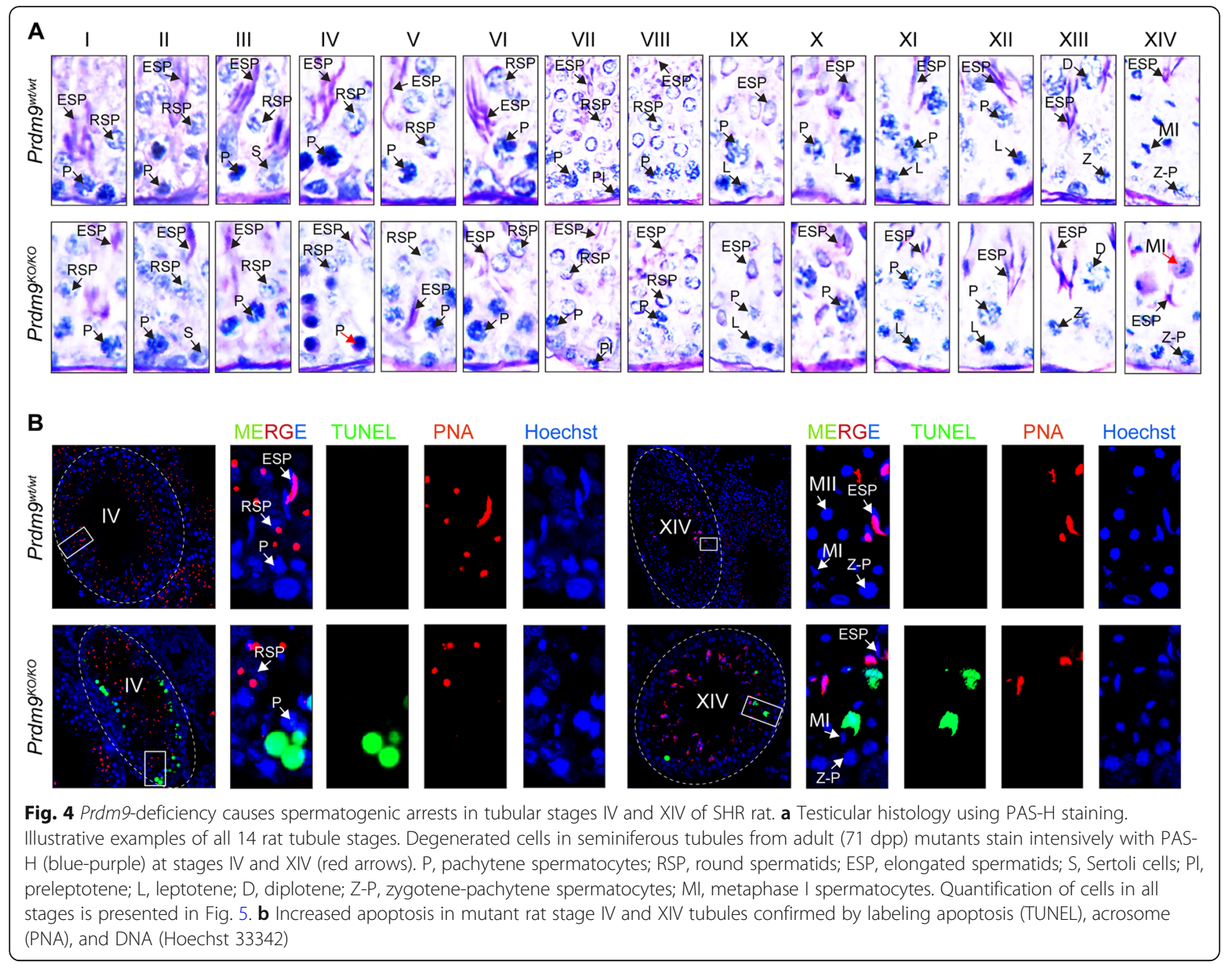

spermatocytes in stage XIV (corresponding to mouse stage XII; $P=0.015)$ of Prdm9-deficient testes, indicative of two types of meiotic arrests. In agreement with this conclusion, the mutant stages V to XII contained less pachytene spermatocytes (all eight $P$ values $<0.024$ ) and mutant stage XIV both less late primary spermatocytes $(P<0.0001)$ and less metaphase II spermatocytes $(P=$ $0.020)$ compared to the controls. In addition, stages VIII, $\mathrm{X}$, and XI of mutant tubules contained elevated numbers of leptotene spermatocytes (all three $P<0.035$ ), which may indicate prophase I delay. Altogether, the histopathology results suggested that the ablation of the rat Prdm9 function caused partial arrests of meiosis at stages IV and XIV, a delayed meiotic prophase I, and incomplete spermiogenesis failures in stages IV and V.

To confirm these arrests of spermatogenesis, we inspected adult rat testicular sections for apoptosis using terminal deoxynucleotidyl transferase dUTP nick end labeling (TUNEL) and revealed that $\operatorname{Prdm} 9^{K O / K O}$ had a $7-$ fold higher mean number of apoptotic cells per all tubules in comparison to $\operatorname{Prdm} 9^{w t / w t}$ and $\operatorname{Prdm} 9^{K O / w t}(P<$
0.001 for both cases; LRM and Tukey's test). To discern the germ cell types undergoing apoptosis, we combined these data with the results of anti-PIWIL1 immunohistochemistry (Fig. 6b, c). The PIWIL1 protein is expressed in pachytene spermatocytes and spermatids [32, 33]. Parallel analysis of 221 apoptotic tubules on neighboring TUNEL and anti-PIWIL1-hematoxylin-stained sections revealed that the majority of apoptotic cells (means of 82 to $88 \%$, total 1059$)$ were spermatocytes $(P<0.001$ for both comparison of mutants to $\operatorname{Prdm} 9^{w t / w t}$ and to $\left.\operatorname{Prd} m 9^{K O / w t}\right)$. The mean number of apoptotic round spermatids per tubule in $\operatorname{Prdm} 9^{K O / K O}$ also exceeded that in combined $\operatorname{Prdm} 9^{K O / w t}$ and $\operatorname{Prdm} 9^{w t / w t}$ (Fig. 6b, $P=$ 0.0044), supporting the results of PAS-H staining. To further confirm the partial arrests of meiotic prophase I and metaphase, apoptotic cells were detected by the TUNEL assay on adult testicular sections co-labeled for acrosome (peanut agglutinin or PNA) and nucleus (Hoechst 33342) (Fig. 4b). Tubular stages IV and XIV in mutant testes carried more apoptotic cells (means of three testes 4.5 and $4.0 \%$ ) than two wild-type controls 

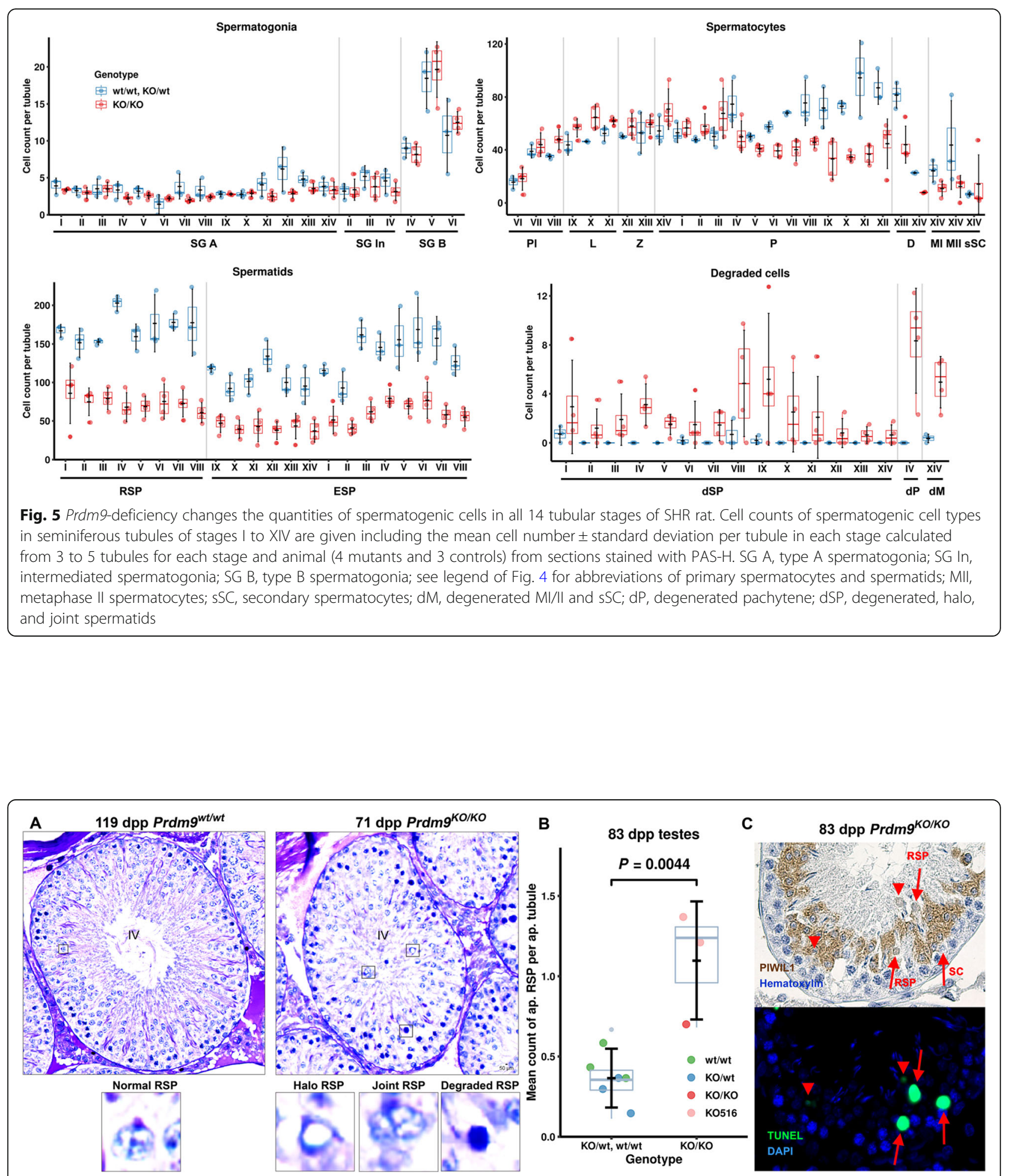

Fig. 6 Rat PRDM9 affects postmeiotic development of round spermatids. a Examples of normal and defective spermatids from wild-type and Prdm9-deficient SHR males on PAS-H stained testicular sections. The means counted in mutant versus control in all 14 stages are in Fig. 5 . $\mathbf{b}, \mathbf{c}$ Increased apoptosis during postmeiotic development of Prdm9-deficient SHR testes. b Mean counts of apoptotic round spermatids per apoptotic tubule were scored from randomly chosen apoptotic tubules (18 to 32 per animal, total 221 tubules from 9 animals), plotted, and evaluated using LRM. The average counts of mutant and control samples were $1.1 \pm 0.4$ and $0.4 \pm 0.2$, respectively. c Round spermatids (RSP) were distinguished on neighboring TUNEL-DAPI and anti-PIWIL1-Hematoxylin-stained sections from spermatocytes (SC); representative images (the same tubule) are shown 
( 0.25 and $0.35 \%$, respectively; both $P<0.007$, generalized linear model or GLM). The close-to-complete midpachytene arrest present in $\mathrm{B} 6-\mathrm{Prdm} 9^{K O / K O}$ mutants [14, 34] is mild in the SHR mutants. Thus, the decreased sperm count in the Prdm9-deficient rats can be explained by increased apoptosis during at least three tubular stages, IV (mid-pachytene spermatocytes and round spermatids), XIV (metaphase spermatocytes), and $\mathrm{V}$ (round spermatids).

\section{Rat PRDM9 is important for efficient spermiation}

Mature rat spermatids (step 19 or S19) align at the luminal side of the seminiferous epithelium and are released into the tubular lumen during rat stage VIII in a process called spermiation [35]. To assess spermiation efficiency in $\operatorname{Prdm} 9$-deficient rats, we inspected the tubular stages IX and X from the rat testicular sections stained with PAS-H (Additional file 1: Fig. S4, Additional file 2: Table S3). Mature S19 wild-type SHR spermatids were rarely retained within the epithelium in stage IX $(0.5 \pm 0.4$ per tubule), which contrasted with stage IX of Prdm9-deficient SHR $(1.5 \pm 0.2 ; P=0.03, \mathrm{GLM})$. The S19 spermatid retention difference was also detected in wildtype versus mutant tubular stage $\mathrm{X}(0.2 \pm 0.1$ versus $1.8 \pm 0.4 ; P=0.01$, GLM). These results suggested decreased spermiation efficiency. Thus increased apoptosis, abnormalities of round spermatids, and spermiation failure contribute to the reduced spermiogenic function of Prdm9-deficient rats. Altogether, our results show that PRDM9 is also required for normal rat haploid male gamete development and release.

\section{Inactivation of Prdm9 leads to stage IV and XII arrests of PWD spermatocytes}

To test the generality of two partial arrests of meiosis I at mid-pachytene and metaphase stages of Prdm9-deficient males, we used a Prdm9-deficient sterile PWD mouse male with gross reduction of sperm count [14]. We analyzed tubular stages IV and XII using PAS-Hstained testicular sections of adult Prdm9-deficient and control mouse PWD males (Additional file 1: Fig. S5, Additional file 2: Table S4). Comparing to wild-type PWD, we found increased numbers of degenerated pachytene spermatocytes in stage IV $(4.9 \pm 0.5$ versus $0.0 \pm 0.0 ; P<0.001$, GLM) and of metaphase cells in stage XII ( $3.2 \pm 0.6$ versus $0.7 \pm 0.4 ; P<0.001)$, suggesting that the two types of meiotic arrest reduce the numbers of Prdm9-deficient male germ cells.

Adult Prdm9-deficient PWD males display only 41\% of wild-type pachytene spermatocytes with complete autosomal synapsis, while the rat SHR-Prdm $9^{K O / K O} \mathrm{mu}-$ tants display $72 \%$ of them, suggesting a weaker stage IV arrest in the rat. Consequently, we expected lower numbers of late primary spermatocytes in mouse tubular stage XII than in the corresponding rat stage XIV. Indeed, despite that the mean numbers of spermatogenic cells of all types in wild-type PWD mouse stage XII versus wild-type SHR rat stage XIV were similar, the mean counts of late primary spermatocytes were lower in the PWD mutant compared to the SHR mutant $(4.1 \pm 0.3$ versus $7.7 \pm 0.4$ ), supporting the stronger mid-pachytene arrest in the PWD-Prdm9 $9^{t m / t m}$ mutant. The sperm counts of the SHR and PWD mutants are about 33\% and $1 \%$ of their corresponding wild-type counts. In agreement with these results, the number of elongated spermatids in stage IV from the SHR rat mutant were 17 to $37 \%$ and from the PWD mutant 0.3 to $3.9 \%$ of the SHR and PWD wild-type counts, respectively. In summary, both SHR rat and PWD mouse Prdm9-deficient males experience incomplete mid-pachytene and metaphase arrests.

\section{Most but not all rat Prdm9-deficient spermatocytes synapse homologous chromosomes}

As the B6-Prdm $9^{K O / K O}$ mouse male displays complete and PWD-Prdm $9^{K O / K O}$ partial pachytene arrest with persistent DSBs and incomplete synapsis [14, 34], we assayed adult rat pachytene nuclei by immunolabeling of the central element of the synaptonemal complex, the SYCP1 protein, and the DSB marker $\gamma \mathrm{H} 2 \mathrm{AX}$ (Fig. 7). The synaptonemal complex provides a scaffold for the alignment of homologous chromosomes and the central element keeps the homologs together through their entire length (homologous synapsis). Phosphorylated histone $\mathrm{H} 2 \mathrm{AX}(\gamma \mathrm{H} 2 \mathrm{AX})$ is found in the vicinity of DSBs, but it also localizes to the $\mathrm{X}$ and $\mathrm{Y}$ chromosomes (sex body) at later meiotic stages (reviewed in [1]). Unlike Prdm9-deficient PWD males that carry 40\% of normal (complete synapsis) pachytene spermatocytes [14], rat mutants displayed $78 \%$ (12 males, 729 nuclei) and wildtype SHR rats $96 \%$ normal pachytene spermatocytes (Fig. 7a). Four of 12 Prdm9-deficient males had a deletion of 20 codons in the PR/SET domain (516-bp deletion of total genomic DNA) and 72\% normal pachynema while the other eight carried only truncating frameshift mutations $(80 \%)$. There were no significant differences in the percentage of normal pachytene cells with fully synapsed autosomes between these four versus eight Prdm9-deficient rats $(P=0.09, \mathrm{GLM})$. Consistently, the testicular weights and sperm counts of these two Prdm 9 deletion types were also similar (Fig. 2). To confirm the role of rat PRDM9 in synapsis, chromosome spreads from adult testes were also labeled using antibodies against the HORMAD2 protein that decorates asynapsed homologous chromosomes during pachynema ([36]; Fig. $7 \mathrm{~b})$. Ninety-five percent of pachytene spermatocytes from $\operatorname{Prdm} 9^{K O / w t}$ but only $62 \%$ from SHR-Prdm $9^{K O / K O}$ animals were normal $(P<0.0001, \mathrm{GLM})$. Thus, rat SHR 

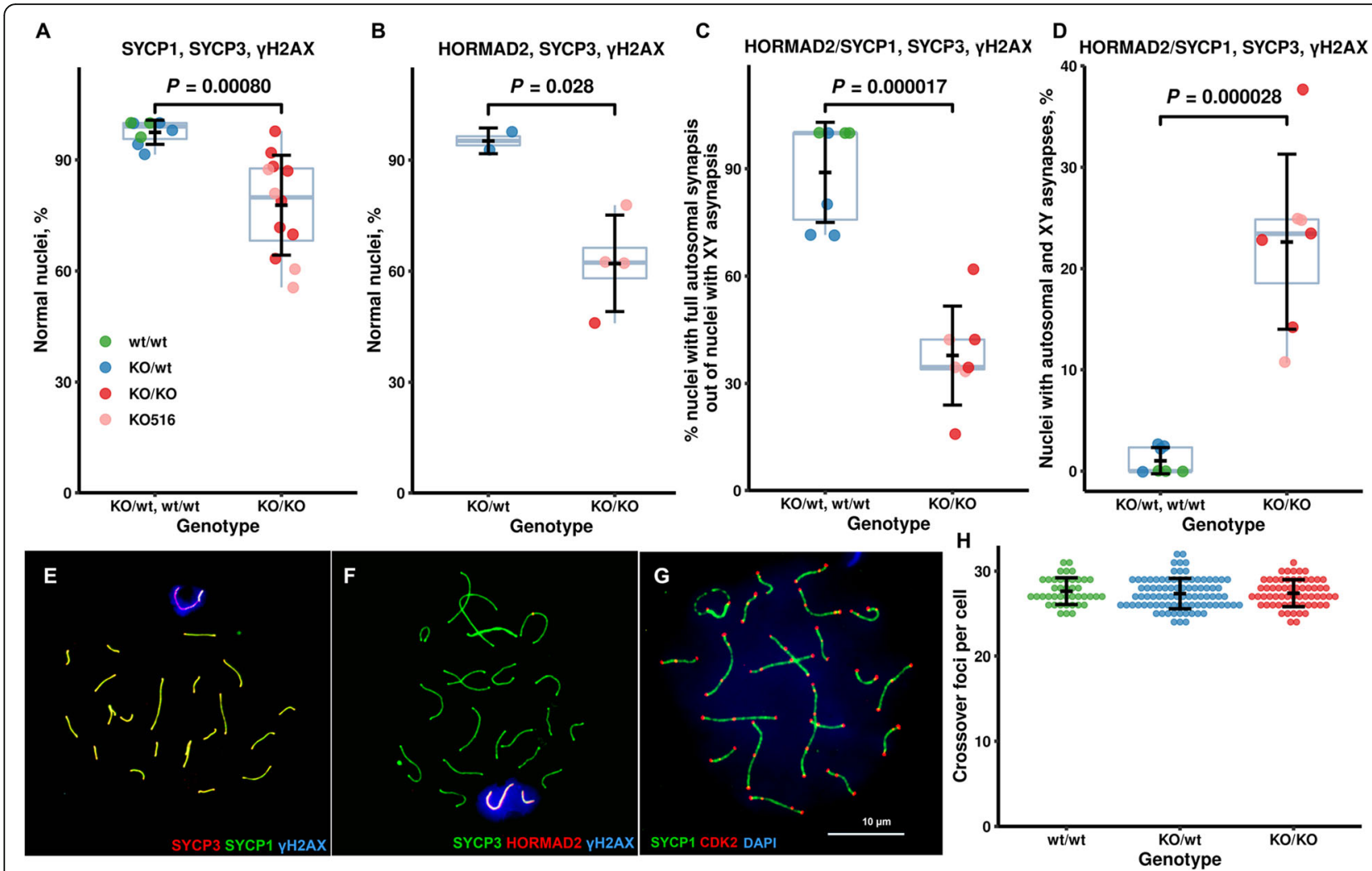

Fig. 7 Decreased homologous synapsis but similar crossover rate in SHR males with Prdm9 deletions compared to wild-type. a, b Percentage of normal pachytene spermatocytes (with all autosomes synapsed). Each dot represents a single animal (over 50 cells). Antibodies used for the staining of chromosomal spreads are given in the headings of each graph. Nuclear spreads used for the analysis of autosomal synapsis in both a and $\mathbf{b}$ were used for the analysis of $X Y$ synapsis in $\mathbf{c}$ and $\mathbf{d}$. $\mathbf{c}$ Percentage of nuclei with full autosomal synapsis out of nuclei with $X Y$ asynapsis in Prdm9-deficient and control rat testes. $\mathbf{d}$ percentage of nuclei with both autosomal and XY asynapsis in Prdm9-deficient and control rat testes. e, f, Examples of normal pachytene cells. Immunocytochemistry with antibodies against: e Synaptonemal complex (SYCP1, SYCP3) and chromatin surrounding DSB sites ( $\gamma H 2 A X)$; f SYCP3, $\gamma H 2 A X$, and unsynapsed chromosomal axes (HORMAD2). See Additional file 1: Fig. S6 for the images of representative nuclei from Prdm9-deficient males. Differences between Prdm9 genotypes were analyzed using LRM with subsequent Tukey test and Holm adjustment for multiple testing. g Representative image of chromosomal spread from a Prdm9-deficient rat immunostained for cyclindependent kinase 2 (CDK2) and synaptonemal complex (SYCP1), confirming that CDK2 localizes both to crossover nodules and telomeres as in the mouse. $\mathbf{h}$ Counts of autosomal crossover nodules per cell ( $N=2$ animals for both Prdm9 $9^{K O} / \mathrm{wt}$ and $\operatorname{Prdm} 9^{K O / K O}, N=1$ for wild-type)

males require PRDM9 for efficient synapsis, but to a lesser degree than mouse PWD males and unlike B6 males, where PRDM9 is nearly essential for synapsis [14].

\section{Rat PRDM9 is important for efficient synapsis of sex chromosomes}

To check whether PRDM9 also supports synapsis of rat sex chromosomes, we analyzed spread nuclei of pachytene spermatocytes from adult testes using immunolabeling (Fig. 7c, d). Seven mutant testes carried 192 of 549 (35\%) and seven controls (3 wild-type and 4 heterozygous Prdm9 males) 42 of 803 (5\%) cells with XY asynapsis. Eighty-six percent (36 of 42) of control cells but only 35\% (68 of 192; Fig. 7c) mutant cells displayed complete autosomal synapsis, thus probably being late pachynema. The remaining 124 Prdm9-deficient spermatocytes (23\% of $549,65 \%$ of 192 ) with both sex and autosomal asynapses were rare in the controls $(0.7 \%$ of 803, $14 \%$ of 42; Fig. 7d) and represented aberrant cells. These results suggest that rat Prdm9 is required for efficient XY synapsis.

\section{Rat PRDM9 supports repair of DSBs and does not affect the crossover rate}

Mouse PRDM9 is important for efficient DSB repair [12, 34]. To assess the effect of PRDM9 on repair of meiotic DSBs in the rat, we analyzed spread testicular nuclei from Prdm9-deficient adult spermatocytes. Immunostaining for synaptonemal complex, centromeres, and early stages of DSB repair (RAD51/DMC1) revealed a few RAD51/DMC1 foci on autosomes and multiple foci on sex chromosomes in normal early pachytene spermatocytes (Additional file 1: Fig. S6m-p). All RAD51/ DMC1 signal disappeared in normal late pachynema (Fig. S6q). However, abnormal cells displayed many 
strong RAD51/DMC1-stained foci on asynapsed chromosomes (Fig. S6r), suggesting that PRDM9 is important for efficient repair of programmed DSBs to crossovers.

Because the sperm presence in the mouse lacking Prdm9 function correlates with crossover rate [14], we analyzed the number of meiotic crossovers in rats with different $\operatorname{Prdm} 9$ copy numbers, including SHR$\operatorname{Prdm} 9^{w t / w t}$ and SHR-Prdm $9^{K O / K O}$ males. Spermatocytes were immunostained with antibodies to the CDK2 protein that localizes to crossover sites in mouse meiotic prophase ([37]; Fig. 7g). All Prdm9-deficient spermatocytes with SYCP1 and CDK2 signals found (63 from two males) were fully synapsed. Both Prdm9-deficient males tested carried on average 27.4 autosomal crossovers per cell, the same as three control males $(27.4 \pm 0.2$; Fig. $7 \mathrm{~h})$, indicating no effect of $\operatorname{Prdm} 9$ on the mean crossover rate of rat males.

\section{The reduced fertility parameters of Prdm9-deficient rats change with age}

Prdm9 affects delayed fertility of intersubspecific mouse hybrid males [6]. To uncover the age-dependent effects of Prdm 9 on rat fertility, we analyzed various fertility parameters at multiple time points up to $250 \mathrm{dpp}$. The Prdm9-deficient animals displayed lower fertility parameters at all ages. Except for body weight used as negative control, all fertility parameters tested started to decline in SHR-Prdm $9^{K O / K O}$ but not in control animals after about 100-150 dpp (Fig. 8).

To assess male fertility more directly, we crossed the rat males and analyzed the offspring production (Fig. 2e, f). In agreement with their testicular weight and sperm counts, the Prdm9-deficient males sired less pups after 150 dpp, thus validating the effect of PRDM9 on agedependent fertility.

\section{Inactivation of rat Prdm9 leads to premature ovarian failure}

PWD and B6 Prdm9-deficient mouse females are sterile, as they form very few follicles and lose all oocytes before adulthood [12, 14]. To explain the decreased ovarian weight of the Prdm9-deficient rats, we checked the effect of Prdm9 on follicular development and age of fertility. Folliculogenesis starts with formation of rat primordial follicles on $2 \mathrm{dpp}$. Our analysis revealed 25\% primordial follicles in SHR-Prdm9 $9^{K O / K O}$ compared to control females at $2 \mathrm{dpp}$ (Fig. 3f), indicating that the majority of oocytes are lost before the onset of follicular development. Primary, secondary, and small antral follicles can be observed beside primordial follicles in juvenile rats

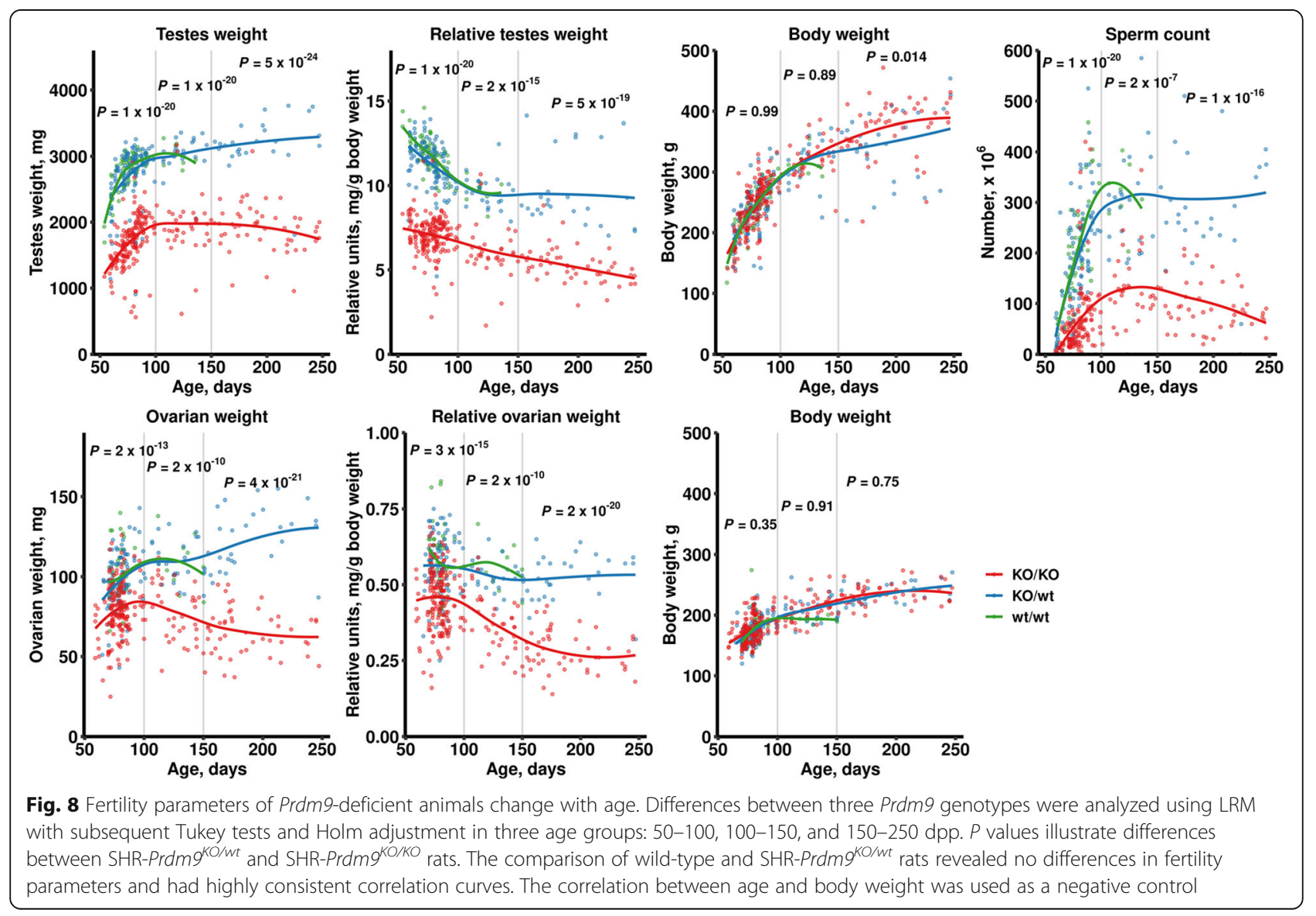


before the onset of estrus on $21 \mathrm{dpp}$. The mean total number of follicles in the mutant was only $7 \%$ of controls at $21 \mathrm{dpp}$ and almost no primordial follicles were detected. This decreased size of the oocyte pool likely contributes to a decreased littersize. Prdm9-deficient rats contained no follicles at $180 \mathrm{dpp}$, which contrasted with the controls (Fig. 3f, g). The paucity of oocytes explains the lack of offspring in mutant females after $150 \mathrm{dpp}$ (Fig. 3d), despite being mated at this age (Fig. 3e), and it is also reflected by the decreasing ovarian weight (see above). These phenotypes of the SHR-Prdm $9^{K O / K O}$ females resemble the human Premature Ovarian Failure syndrome, where the oocyte pool is exhausted early in age leading to sterility [38]. Altogether, these results suggest the importance of rat $\operatorname{Prdm} 9$ for oocyte survival and follicle development.

\section{Rat PRDM9 affects the duration of meiotic prophase I in both sexes}

Partial meiotic arrest in semifertile mouse hybrids, which is alleviated by manipulating $\operatorname{Prdm} 9$ dosage, is accompanied by meiotic delay [6] and SHR-Prdm $9^{K O / K O}$ adult males displayed increased leptotene counts compared to controls in several tubular stages. To validate the requirement of $\operatorname{Prdm} 9$ for normal meiotic progression kinetics in SHR males, we analyzed the first wave of rat spermatogenesis by immunohisto- and cytochemistry. We inspected sections of prepubertal PRDM9-deficient and control (wild-type and $\operatorname{Prdm} 9^{K O / w t}$ ) SHR testes immunolabeled for chromatin surrounding DNA breaks under repair $(\gamma \mathrm{H} 2 \mathrm{AX})$ and cytoplasmic piwiRNA particles (PIWIL1). Fifty-two percent of testicular tubules in 21-dpp controls (3 males, 154 to 368 tubules scored) but only $8 \%$ tubules of their mutant littermates (565 tubules from two animals) were classified as containing cells in pachynema (Fig. 9a, b; $P=0.042$ ).

To confirm the meiotic delay found at the tissue level also on cells, we immunostained spreads of testicular nuclei from 18-dpp males for synaptonemal complex markers. Pachytene spermatocytes formed about $8 \%$ of all spermatocytes in the mutant testes compared to $21 \%$ in controls (Fig. 9c). To evaluate the association of the mutant rat meiotic prophase I delay with partial meiotic arrest, we inspected testicular sections from 21-dpp SHR males for apoptosis using TUNEL staining. There was a higher percentage of tubules containing multiple apoptotic cells in the mutant compared to control testes (means of 24 versus 13\%), suggesting a weak arrest of prophase I (Fig. 9d). This conclusion is supported by the analysis of PAS-H staining and apoptosis in tubular stage IV of adult rat mutant testes (see above).

Both male and female Prdm9-deficient SHR animals displayed age-dependent fertility. To evaluate the importance of PRDM9 for the timely meiotic progression in SHR females, we staged spread nuclei from embryonic ovaries, where the single wave of female meiotic prophase I takes place (Fig. 9e). We used markers of synaptonemal complex (SYCP3 and SYCP1) and chromatin surrounding DNA breaks under repair $(\gamma \mathrm{H} 2 \mathrm{AX})$. Seven to $15 \%$ oocytes in four pairs of control ovaries at 21 days post coitum $(\mathrm{dpc})$ were pachytene. However, two pairs of littermate mutant ovaries contained no pachytene nuclei (Fig. 9e; $P=0.015$, LRM), validating the prophase I delay of female rat meiosis in the absence of PRDM9.

Our results show that PRDM9 deficiency delays the onset of pachytene stage and slows down the progression of meiotic prophase I in SHR rats of both sexes.

\section{Rat PRDM9 trimethylates $\mathrm{H} 3 \mathrm{~K} 4$ and guides most meiotic DSBs}

In order to assess the function of rat PRDM9 in DSB positioning, genome-wide distributions of DSBs were analyzed in two related rat strains carrying the same $\operatorname{Prdm} 9$ allele, WKY and SHR, and in the BN/RIJHsd strain that harbors a distinct Prdm9 allele (Fig. 10, right) by singlestranded DMC1-bound DNA sequencing (SSDS). The identified DSB hotspots overlapped by $88 \%$ between the SHR and WKY strains, but only by $3 \%$ between the BN and WKY strains (Fig. 10, Additional file 1: Fig. S7). DSB hotspots were stronger on chromosome $\mathrm{X}$ than on autosomes (Additional file 1: Fig. S8), as expected [15]. The strain overlap data suggest that PRDM9 controls most sites of rat recombination initiation. To address the epigenetic function of rat PRDM9, we generated H3K4me3 profiles from the BN and WKY testes. The profiles differed at variable hotspot sites (Fig. 10), thus validating that rat PRDM9 displays in vivo H3K4-methyltransferase activity. Relocation of meiotic DSBs to H3K4me3 at promoters and other functional genomic elements in the Prdm9 knockout B6 mice was suggested as a possible cause of infertility. The alleviation of the infertile phenotype in the Prdm9-deficient rats could therefore be caused by the existence of another factor directing the recombination machineries away from these sites. The existence of this factor was hypothesized based on the analysis of the sites of PRDM9-independent human crossovers [23]. To check this possibility, genome-wide distribution of meiotic DSBs was compared between an adult SHR male carrying the homozygous KO39 truncating deletion (Fig. 1) and its wild-type littermate. The distribution of DSB hotspots in rats lacking PRDM9 was similar to that in mice: a large percentage of hotspots coincided with the default H3K4me3 marks, many of which were at gene promoters (Fig. 10 and see below). The relocation of DSB hotspots in the Prdm9-deficient rat to the default H3K4me3 sites (98.6\% of 21,586 SHR DSB hotspots) and the similarity of the phenotypes of the four rat $\operatorname{Prdm} 9$ deletions support the view that the 


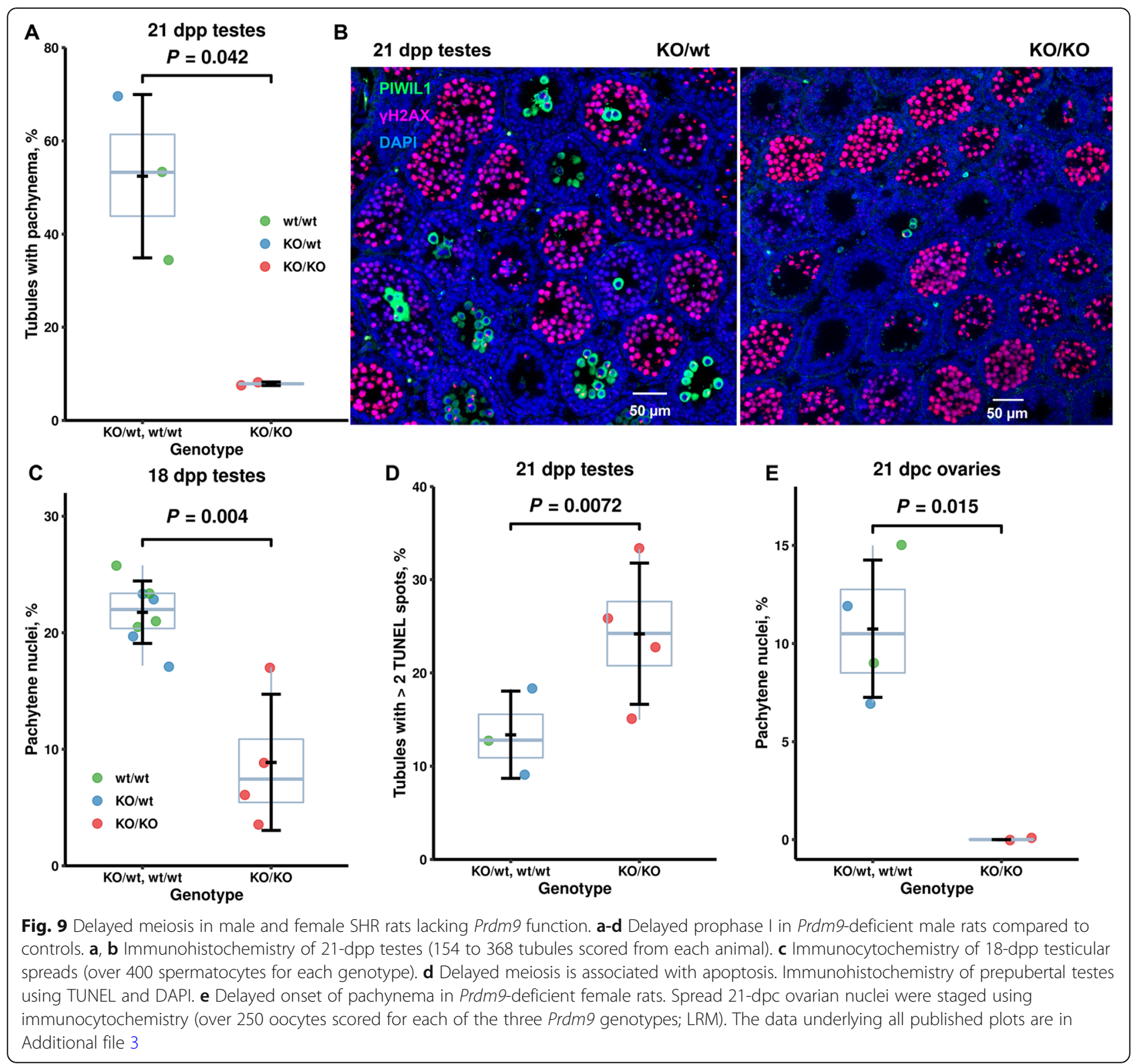

truncating mutations result in null alleles. Therefore, it is unlikely that the rat has other factors besides PRDM9 to avoid recombination at default $\mathrm{H} 3 \mathrm{~K} 4 \mathrm{me} 3$ sites.

\section{Prdm9-independent hotspots tend to localize to orthologous regions}

To learn about the evolutionary and functional properties of DSB hotspots (HSs), we analyzed the conservation of rat (SHR) and mouse (B6) HSs by mapping the rat HSs to the mouse genome assembly (see the "Methods" section). As expected from the analysis done in the mouse [14, 15], overlaps between wild-type HSs and $\operatorname{Prdm} 9^{K O / K O}$ HSs were only 1 to $2 \%$ between the species (Fig. 11a). However, $40 \%$ of B6-Prdm $9^{K O / K O}$ HSs corresponded to $37 \%$ of SHR-Prdm $9^{K O / K O}$ HSs (Fig. 11a).
Therefore, the recombination initiation maps were similar in the two PRDM9-deficient rodent species. This is analogous to different species in finches and budding yeast that naturally lack $\operatorname{Prdm} 9[17,18]$.

In general, $36 \%(11,888$ of 33,660$)$ of rat and $41 \%$ $(12,716$ of 30,929$)$ of mouse Prdm9-independent HSs localized to evidence-based promoters (defined by Ensembl, see the "Methods" section), in contrast to wild-type HSs from SHR rats (343 of 19,967 or 2\%) or B6 mice (900 of 19,528 or $3 \%$ ). Our analysis revealed that $66 \%$ of conserved Prdm9-independent HSs overlapped promoters, in contrast to $25 \%$ of mousespecific and $18 \%$ of rat-specific Prdm9-independent HSs (Fig. 11b). When the set of promoters was narrowed to promoters of coding genes, 27\% (8229 of 


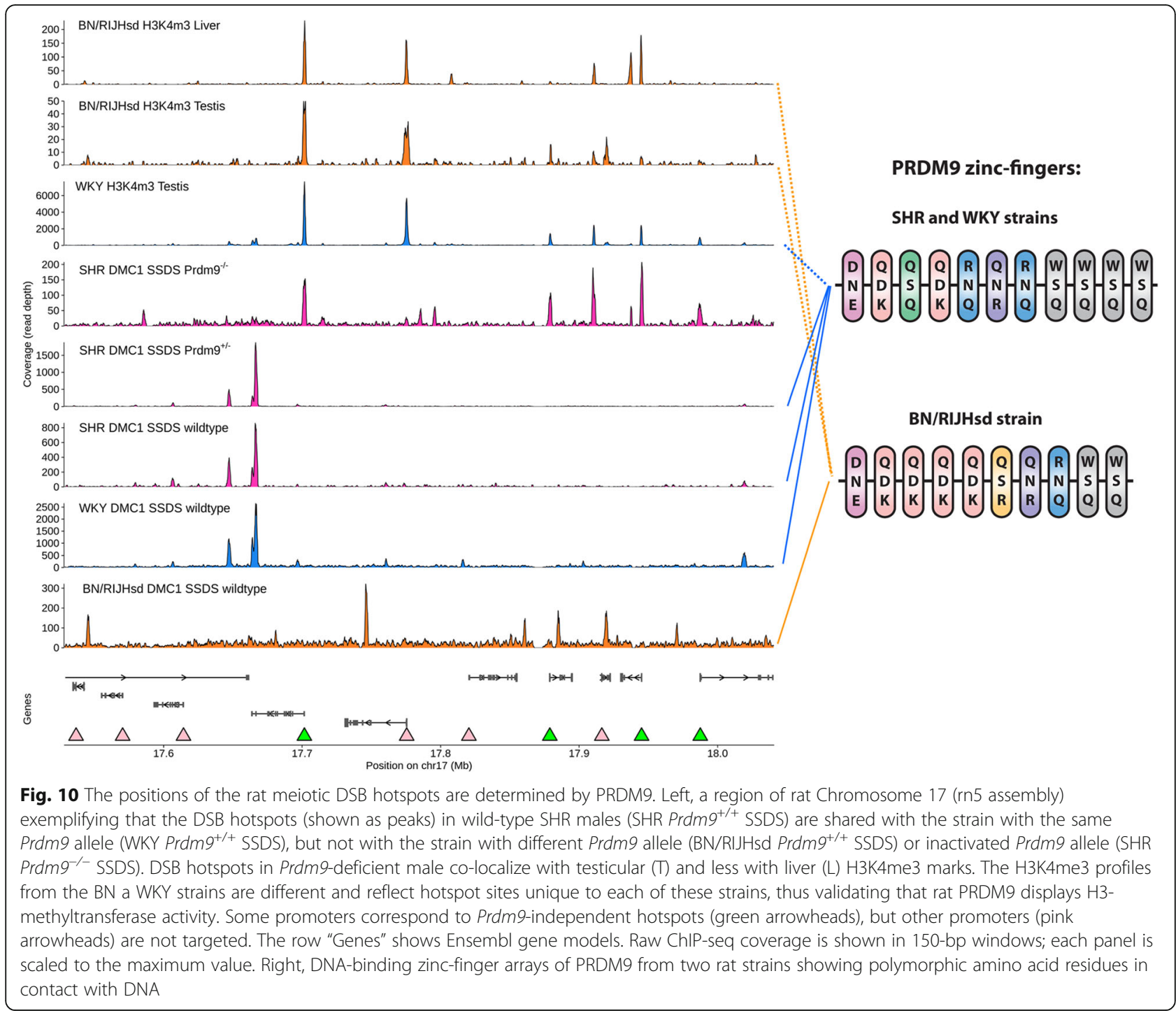

30,929) of mouse HSs and 23\% (7687 of 33,360) of rat HSs fell within their coordinates.

The general analysis of promoters of coding genes revealed that $65 \%(14,237$ of 21,956$)$ of mouse promoters overlapped with $73 \%(14,447$ of 19,719$)$ of rat promoters (see the "Methods" section). Sixty-eight percent of the overlapping promoters contained HSs in either one or both rodent species, and $43 \%$ of conserved promoters overlapped conserved hotspots (Fig. 11c).

\section{Discussion}

We show that PRDM9 directs most sites of meiotic DSBs in the male rat, as it is in the mouse $[39,40]$ and man [5]. The relocation of rat DSBs to default (Prdm9independent) H3K4me3 sites upon deletion of Prdm9 occurs in the B6 laboratory mouse [15], where Prdm9 deficiency causes complete sterility [12]. The partial fertility of the Prdm9-deficient SHR rats therefore might be due to faster and/or more efficient DSB repair of the default H3K4me3 sites in Prdm9-deficient rats compared to mice. One mechanism of generating mature germ cells could be bypassing the pachytene checkpoints with unrepaired DSBs. However, this would lead to aneuploid germ cells and defective offspring, while the Prdm9-deficient SHR animals produced fertile pups of normal appearance. Moreover, our examination of male DSB repair suggested that many DSBs are being repaired and even generate a normal number of crossovers. A comparison of $\operatorname{Prdm} 9$-deficient mice with various genetic backgrounds that differ in fertility revealed a significantly higher crossover rate (COR) in sperm-producing versus azoospermic males [14]. All 19 mouse autosomes are acrocentric; this implies that mouse COR per autosome and per autosomal arm are identical. Here we show that both wild-type and Prdm9-deficient SHR males display on average 27.4 autosomal crossover nodules per 


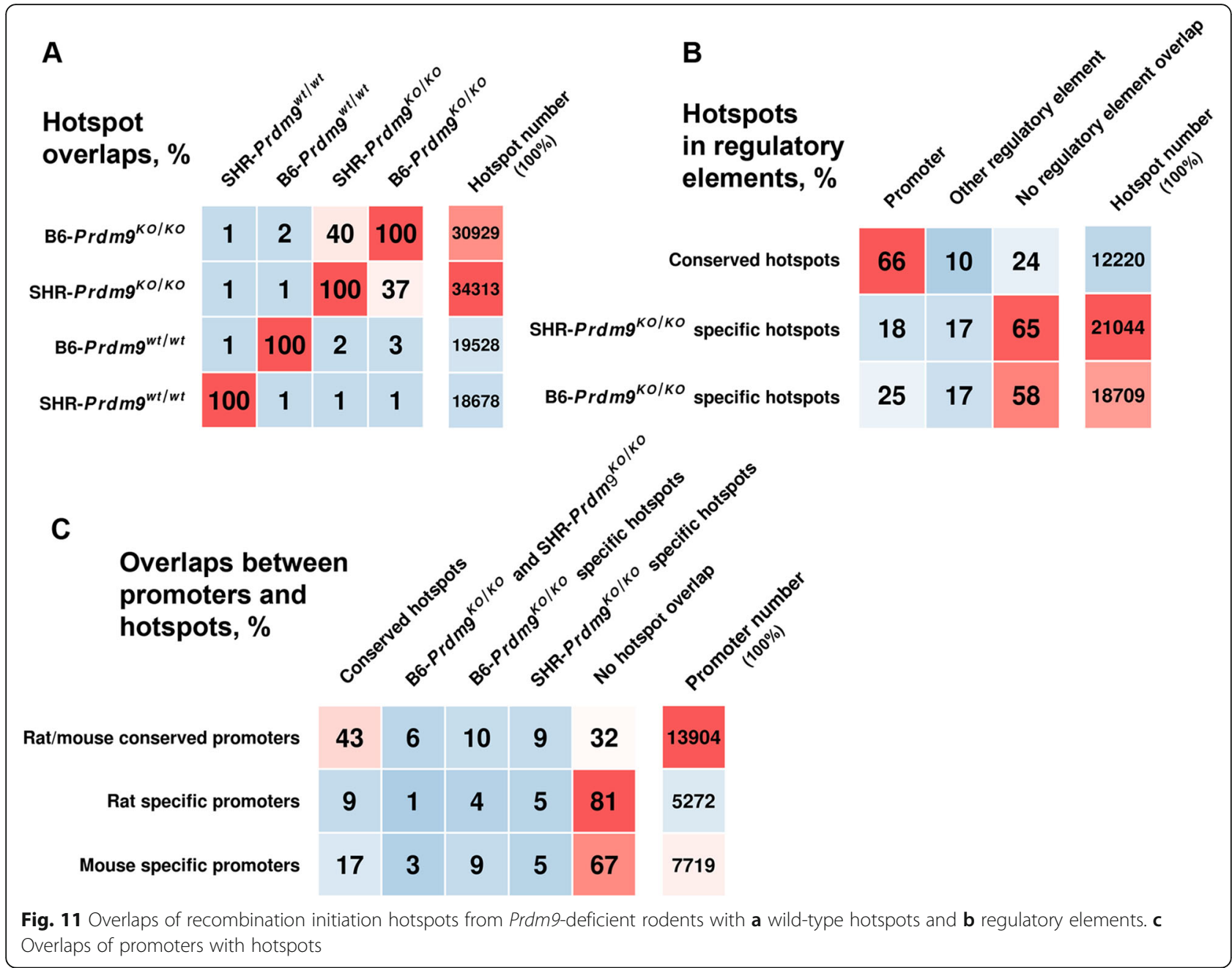

spermatocyte. Only eight of 20 rat autosomes are acrocentric, indicating that if one obligatory crossover per autosomal arm is required to ensure proper segregation, the COR should be at least 32 nodules per cell. We deduce that one crossover per rat autosome is sufficient (see also [41]) and that we can directly compare the autosomal rates in the mouse and rat. The mean SHR rate of 1.37 nodules per autosome (27.4/20) is more similar to the COR of sperm-producing Prdm9-deficient mouse males (ranging from 1.38 to 1.56 ) than to the COR of azoospemic Prdm9-deficient males (1.19 to 1.28), suggesting that COR could be associated with the fertility parameters of the Prdm9-deficient rat males. However, the SHR mutant carries a much higher percentage of wild-type sperm than PWD mutants (40 versus $1.2 \%$ ) despite lower mean COR (1.37 versus 1.54 ), indicating that additional factor(s) besides COR play a role.

Unlike Prdm9-deficient B6 mice, where both sexes display nearly complete arrest in prophase I, PWD mutant males show only partial arrest [14], and CAST/EiJ mutant males but not females display complete arrest [26]. In contrast, both sexes of Prdm9-deficient SHR rat displayed age-dependent fertility and meiotic prophase I slowdown. Meiosis takes 19 days in the rat and 14 days in the mouse adult males (prophase I takes 18.5 and 13 days, respectively) [42]. The duration of female meiosis is 8 to 11 days in the rat [43] and 7 days in the mouse [44, 45]. Meiosis takes shorter time in the mouse compared to the dog, which harbors a non-functional PRDM9-encoding gene [22]: 17 days in dog males [46] and 33 to 54 days in dog females [47]. Longer meiotic prophase I gives the cell more time to synapse homologous chromosomes and repair programmed DNA breaks in order to pass the meiotic checkpoints. We therefore propose that one of the factors affecting the differences in fertility of Prdm9-deficient animals could be the duration of meiosis.

The SHR strain is an excellent rat model of human spontaneous hypertension [48] and might also be a better model of meiotic DSB initiation than multiple laboratory mouse strains [14], because some SHR females lacking functional $P R D M 9$ can produce offspring, as can 
at least one human female [23]. Moreover, these mutant rat females display phenotypes resembling the human syndrome Premature Ovarian Failure.

DSB targeting via mouse PRDM9 has been shown to correlate with the histone $\mathrm{H} 3$ methylation profiles [26, 49, 50]. We show that H3K4me3 peaks correlate with PRDM9-dependent hotspots in rat strains (Fig. 10). We found no difference between phenotypes of rats carrying truncating versus internal PR/SET-domain (catalytic) deletions, suggesting that this domain and thereby the H3K4 and/or H3K36 trimethylation are essential for PRDM9 function as in the mouse [51]. However, the mRNA with the internal deletion was produced from the same locus as mRNA encompassing truncating deletion and it has not been possible to determine the ratio of these mRNAs. Reduced protein expression of the product expected from the mRNA with internal SET/PR domain deletion was found. Therefore, we are uncertain whether or not the reason this mutation behaved as a null is because loss of 20 codons of the PR/SET domain was sufficient, or because too little PRDM9 was actually expressed. In any case, all four deletions are compatible with offspring production.

Mouse $\operatorname{Prdm} 9$ has been identified as hybrid sterility gene $[6-8,52]$ via interaction with the Hstx2 locus affecting COR [53-55] and via differential erosion of recombination sites [9, 39, 56-58]. Our Prdm9-deficient Rattus norvegicus could be now used to test the generality of the role of this epigenetic factor in rodent hybrid sterility.

The mouse pseudoautosomal region (PAR) encompasses PRDM9-independent DSB hotspots, while the recombination in human PARs is determined by PRDM9 $[5,15]$. The rat PAR is not annotated in the reference genome assembly. Thus, it is not possible to assess the DSB activity in or adjacent to the rat PAR using our short-read sequencing approaches. The rat PAR may not be structurally analogous to the mouse PAR [59]. Only three DSB hotspots were shared among all three wildtype strains and the $\operatorname{Prdm} 9^{K O / K O}$ rats. However, since we cannot study PRDM9-independent hotspots at or near the PAR in rats, we may be missing the primary locus at which such hotspots occur.

The two rat PRDM9 wild-type alleles characterized here are the alleles of the parental strains of $\mathrm{BXH} / \mathrm{HXB}$ recombinant inbred strains, BN-Lx/Cub and SHR [48]. The fecundity of the SHR Prdm9-deficient rat offers the possibility to extend the current panel by strains that use new recombination sites (including promoters). These new strains could help to refine the resolution of rat mapping projects.

In addition to the anticipated apoptosis of meiotic pachytene spermatocytes, we also detected increased incidence of defective and apoptotic metaphase I/II cells and spermatids. Our result thus shows that PRDM9 is important for spermiogenesis. This increase of abnormal spermatids in rat $\operatorname{Prdm} 9$ mutants could be interpreted either as an indirect consequence of meiotic defects (like in [60]) or a direct outcome of a $\operatorname{Prdm} 9$ postmeiotic function. The partial metaphase and postmeiotic arrests are helpful to decipher the differences between the percentage of normal pachytene cells and the resulting percentage of normal sperm count in PWD mice and SHR rat. Metaphase arrest was previously found in several types of intersubspecific mouse hybrids (e.g., [61]); our results suggest that it may be affected by the loss of function of Prdm9. Age-dependent fertility has been detected in $(\mathrm{PWK} \times \mathrm{B} 6) \mathrm{F} 1$ mouse hybrids $[6,62]$. Their delayed meiosis was rescued by manipulating the copy number of $\operatorname{Prdm} 9$ [6]. We found delayed meiotic progression in our non-hybrid Prdm9-deficient rat strain (this report) and prepubertal PWD males [14], and thus we can interpret the delayed hybrid fertility as the result of incompatibility of $\operatorname{Prdm} 9$ alleles rather than failed or dominant intergenic interaction. The delayed fertility of $(\mathrm{PWK} \times \mathrm{B} 6) \mathrm{F} 1$ was accompanied by a slowdown of meiosis; delayed repair of meiotic DSBs has been also been found in $(\mathrm{PWD} \times \mathrm{B} 6) \mathrm{F} 1$ hybrids [54]. The postmeiotic function of PRDM9 along with the reduced counts of sperm and ovarian follicles helps to explain our inability to acquire offspring from intercrosses of male and female rats both lacking PRDM9.

\section{Conclusions}

The postmeiotic function of $\operatorname{Prdm} 9$ may indicate that an additional mechanism involving PRDM9 besides repositioning meiotic hotspots may also play a role in speciation. In agreement with this conclusion, we have recently demonstrated that mouse $\operatorname{Prdm} 9$ affects not just the quantity, but also the quality of sperm and spermatids generated by intersubspecific $(\mathrm{B} 6 \times \mathrm{PWD}) \mathrm{F} 1$ mouse hybrids [63, 64]. Mouse males captured in the hybrid zone separating the musculus and domesticus house mouse subspecies usually carry sperm, but its quantity and quality is reduced $[65,66]$. The postmeiotic function of PRDM9 thus might have a similar impact on mouse speciation as the meiotic one.

\section{Methods}

Animals, production of Prdm9 deletions, and genotyping The rats were bred at the Institute of Physiology and Institute of Molecular Genetics of the Czech Academy of Sciences (permissions nos. 66/2014 and 10/2016 issued by the ethics committees), following Directive 86/609/ EEC, Appendix A of the European Community Council of Europe Convention ETS123, and the Czech Republic Act for Experimental Work with Animals (Decree No. 207/2004 Sb, and Acts Nos. 246/92 Sb and 77/2004 Sb). 
The SHR/OlaIpcv strain was reviewed [67]. The Prdm9 mutants were produced using mRNAs of a heterodimeric artificial zinc-finger endonuclease programmed to target the ninth coding exon of the mouse Prdm9 gene (Sigma-Aldrich); these mRNAs were injected into fertilized SHR ova ([68]; Table 1). The Prdm9 $9^{\text {tm1YMat }}$ mutant on the mouse PWD/Ph background (PWD-Prdm $9^{t m}$ ) was described [14]. Genotyping PCR primers (listed in Additional file 2: Table S5) spanning the target site were then utilized to select the rats carrying $\operatorname{Prdm} 9$ deletions. These deletions have been maintained on the SHR background.

\section{Phenotyping}

Body weight (BW) and testes weight (TW) or ovary weight $(\mathrm{OW})$ were measured after dissections. Sperm count (SC) was obtained after thorough mincing of the entire right epididymidis in phosphate-buffered saline $(\mathrm{pH}=7.4)$ at room temperature and the count obtained using a Burker cytometer was multiplied by two. The litter size was estimated at birth; the pups were weaned at about 30 days of age. Preparation of chromosome spreads (slides with surface-spread nuclei) from testicular cells via hypotonic treatment was as published [69]. Immunocytochemistry and histochemistry were done as described [6, 7, 54, 55]; analysis of apoptosis is detailed below. The recombination nodules were counted using CDK2 immunocytochemistry on SYCP1-staged pachytene spermatocytes after subtracting the number of telomeric CDK2 foci. Antibodies are listed in Additional file 2: Table S6. Total RNAs were utilized to quantify mRNA expression levels by real-time qRT-PCR in LightCycler $[7,8]$ using primers shown in Additional file 2: Table S5. Evaluations of significance were done using LRM or GLM.

\section{PRDM9 protein detection in nuclear fractions by Western blotting}

Mouse (12 dpp) and rat (18 dpp) testes were homogenized in hypotonic buffer (10 mM HEPES, pH 8.0, 320 $\mathrm{mM}$ sucrose, $1 \mathrm{mM}$ PMSF, $1 \times$ Complete protease inhibitor cocktail EDTA-free (\#11873580001, Roche) and $1 \times$ phosphatase inhibitor cocktail (\#78420, Thermo Scientific) in a glass Douncer. Six and two testes were used for the mouse, and rat extracts, respectively. Testes suspensions were centrifuged at $1000 \times g$ at $4{ }^{\circ} \mathrm{C}$ for $10 \mathrm{~min}$. Pellets were resuspended in RIPA buffer $(50 \mathrm{mM}$ Tris$\mathrm{HCl}, \mathrm{pH} 7.5,150 \mathrm{mM} \mathrm{NaCl}, 1 \mathrm{mM}$ EDTA, 1\% NP-40, $0.5 \%$ Na-deoxycholate, $0.1 \%$ SDS, $1 \times$ Complete protease inhibitor EDTA-free and sonicated (4 cycles of $15 \mathrm{~s}$ ON, $15 \mathrm{~s}$ OFF, high power) in a Bioruptor Next-Gen sonicator (Diagenode). Suspensions were centrifuged at 16, $000 \times g$ at $4{ }^{\circ} \mathrm{C}$ for $10 \mathrm{~min}$. Supernatants were used as nuclear fractions. Nuclear fractions $(10 \mu \mathrm{g}$ for mouse and
$30 \mu \mathrm{g}$ for rat) were separated in $4-15 \% \mathrm{TBX}$-acrylamide gradient gel (Bio-Rad) and blotted onto nitrocellulose membranes. The membrane was blocked for at least $1 \mathrm{~h}$ at room temperature $(1 \times$ TBST with $0.5 \%$ milk) and incubated overnight at $4{ }^{\circ} \mathrm{C}$ with affinity-purified rabbit anti-PRDM9 (1: 200) [70] or with guinea pig anti-SYCP3 (1: 3000) [70]. Secondary antibodies were goat antirabbit IgG-HRP (1: 5000) (\#1858415, Pierce) and goat anti-guinea pig IgG-HRP (1: 5000) (\#706-035-148, Jackson Immuno Research). Blots were revealed with Super Signal West Pico Chemiluminescent Substrate (\#34080, Thermo Scientific). The same membrane was used for SYCP3 detection after stripping.

\section{Histology}

Testes and ovaries were fixed overnight in Bouin's fixative at $4{ }^{\circ} \mathrm{C}$, washed in PBS, dehydrated in ethanol series, and stored in $70 \%$ ethanol at $4{ }^{\circ} \mathrm{C}$. The fixed organs were embedded in paraffin, sectioned $(5 \mu \mathrm{m})$, and mounted on glass slides. Sections were then deparaffinized using xylene and rehydrated with ethanol series. For PAS-H staining, sections were incubated with $0.5 \%$ periodic acid (Sigma) for $10 \mathrm{~min}$, washed in tap water for $3 \mathrm{~min}$, and stained with Schiff's reagent (Sigma) for $20 \mathrm{~min}$. Sections were counterstained with Harris hematoxylin (Sigma) for $15 \mathrm{~s}$, washed in tap water for $10 \mathrm{~min}$, and dehydrated with ethanol series and xylene. Whole slides were scanned and digitized with the Zeiss Axioscan.Z1 Slide Scanner with a $20 \times 0.8 \mathrm{NA}$ objective (Carl Zeiss). The open-source software QuPath [71] was used for analyzing digital histology images of testes sections manually. Stages I to XIV of rat seminiferous epithelium cycle were determined as described [35].

\section{Counting and classification of apoptotic cells}

Analysis of cell types undergoing apoptosis was performed in testes of 61 to 92 days old rats (three of each $\operatorname{Prdm} 9^{w t / w t}, \quad \operatorname{Prdm} 9^{K O / w t}, \quad$ and Prdm9-deficient $\operatorname{Prdm} 9^{K O / K O}$ ). Neighboring sections of paraffinembedded testes were treated either with DeadEnd Fluorometric TUNEL System (Promega) or with antiPIWIL1 primary antibody (ab12337, Abcam) followed by Goat Anti-Rabbit conjugate secondary antibody (\#1706515, Bio-Rad), visualization using ImmPACT ${ }^{\mathrm{pu}}$ DAB Substrate (SK-4105, Vector Laboratories, Inc.), and hematoxylin staining. Slides were examined at 400-times magnification. Apoptotic cells were counted in TUNELstained sections in 200 tubules per animal; mean values were calculated from apoptotic tubules and used for further statistical processing. In addition, detailed histological examination was performed in 18 to 28 apoptotic tubules per animal to define the stages of spermatogenesis, at which cells underwent apoptosis. For this purpose, the positions of TUNEL spots were inspected in 
the corresponding PIWIL1-immunostained neighboring sections. Position of the apoptotic cell in the tubule, stage of the neighboring normal cells, color of cytoplasm, color and visible structural features of the nucleus, and the nucleus size, were taken into account. Mean values of total numbers of apoptotic cells per tubule, as well as of spermatocytes and round spermatids separately, were calculated from 18 to 28 tubules per animal and used for further statistical processing. Statistical analysis was performed in $\mathrm{R}$ using multcomp package, applying LRM and subsequently Tukey's test. For immunofluorescent labeling of acrosome and nucleus after TUNEL detection, slides were treated with Peanut Lectin from Arachis hypogaea (peanut) conjugated with Alexa Fluor 568 (PNA; Invitrogen) and Hoechst 33342 (Sigma) as described [63]. TUNEL-PNA-Hoechst slides were scanned with the Zeiss Axioscan.Z1 Slide Scanner with a $20 \times 0.8$ NA objective (Carl Zeiss) and analyzed using QuPath software [71].

\section{Single-strand DNA sequencing (SSDS)}

DMC1 ChIP-SSDS to assess genome-wide DSB distribution using snap-frozen adult testes and its analyses were done as described previously [72, 73]. Sequencing reads were aligned to the rat rn5 genome using a modified version of bwa (0.7.12) and ssDNA-derived fragments were identified using a bespoke ssDNA identification pipeline. DSB hotspots were called using a default hotspot calling pipeline and using only uniquely mapping ssDNA type 1 fragments with an alignment Q-score for both paired-end reads with values over 30 .

\section{Rat-mouse hotspot conservation and annotation}

Coordinates of $\mathrm{B} 6$ and $\mathrm{B} 6-\mathrm{Prdm} 9^{K O / K O}$ hotspots (HSs) were obtained from published SSDS ChIP-seq data (GEO acc. nos. GSM1954835 and GSM1954864, [39]). For detection of HSs conserved between B6-Prdm9 $9^{K O / K O}$ and SHR-Prdm $9^{K O / K O}$, we applied previously described criteria [15], considering two HSs as taking place at the same location only when overlapping within \pm 200 bp distance from the HS centers. For comparative analysis of Prdm9-independent rat versus mouse HS, coordinates of the $\pm 200 \mathrm{bp}$ central HS regions were converted (remapped) from $\mathrm{rn} 5$ to $\mathrm{mm} 10$ genome assembly using UCSC LiftOver binary tool [74] with default parameters, - minMatch $=0.1$, and the chain rn5ToMm10.over.chain.gz. Totally, $94 \%$ of SHR-Prdm $9^{K O / K O}$ (34,313 of 36, $687)$ and $87 \%$ of SHR-Prdm $9^{w t / w t}(18,678$ of 21,589$)$ central $400 \mathrm{bp}$ HS regions were remapped. HS containing extremely long gaps after conversion were excluded from the analysis (specifically, 717 SHR Prdm $9^{w t / w t}$ and 791 SHR-Prdm $9^{K O / K O}$ HS with central region above 800 bp after coordinate conversion). Overlapping rat/mouse HS (central $400 \mathrm{nt}$ ) coordinates were merged and considered as one conserved region. HSs revealing no overlaps within central $400 \mathrm{nt}$ regions were considered non-conserved, B6-Prdm $9^{K O / K O}$ - or SHR-Prdm $9^{K O / K O}$ specific. Coordinates of rat and mouse promoters of coding genes, taken as $2000 \mathrm{bp}$ upstream and $200 \mathrm{bp}$ downstream from the transcription start site, were extracted from the Ensembl Genes via biomaRt $R$ package [75]. Coordinates of rat promoters were converted from rn6 to mm10 with a chain rn6ToMm10.over.chain.gz. The overlapping rat/mouse promoter ranges were merged and considered as one conserved promoter. Location of mouse evidence-based promoters and other functional elements was taken from the Ensembl regulatory build. With the exception of coordinate conversion, all other data operations were performed in $\mathrm{R}$ version 3.4.4 using Bioconductor packages. Ensembl version 94 was used for exploratory analysis of conserved and nonconserved HS sets.

\section{Supplementary Information}

The online version contains supplementary material available at https://doi. org/10.1186/s12915-021-01017-0.

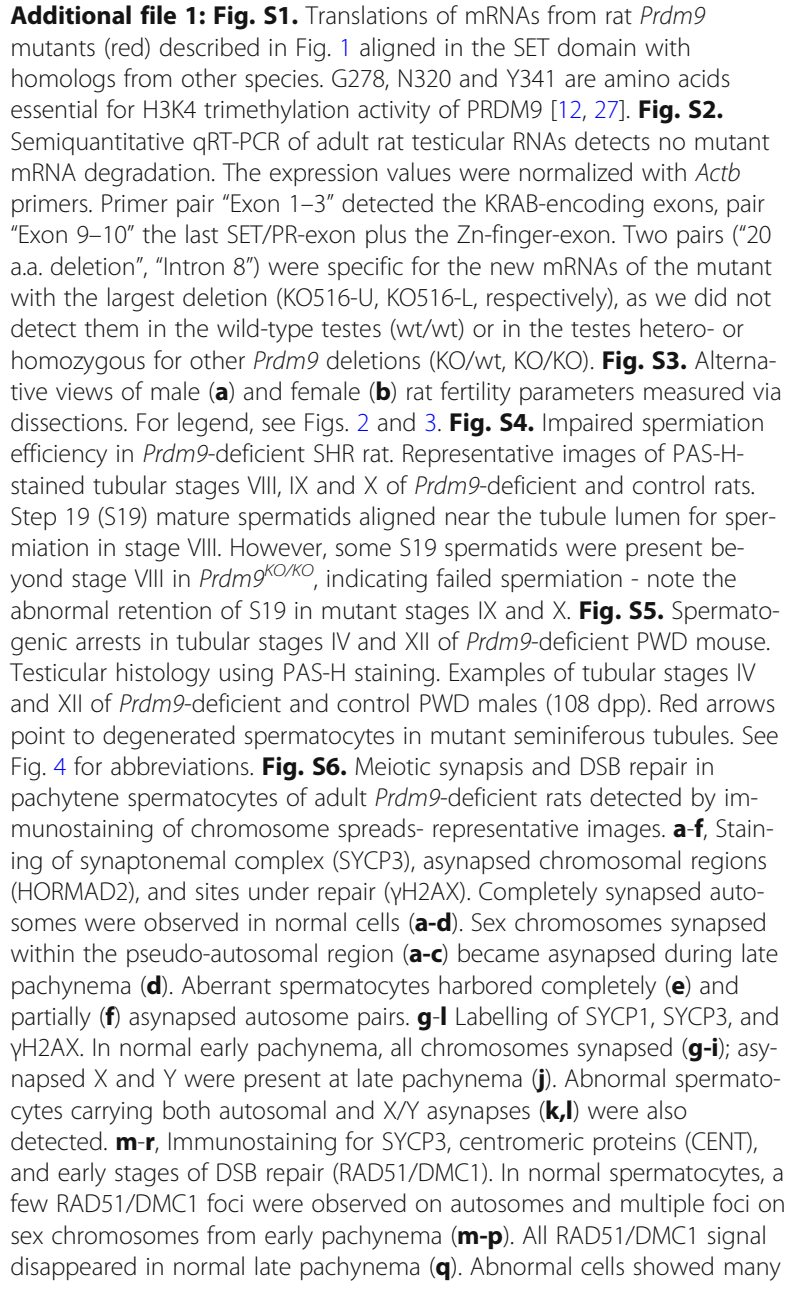

Additional file 1: Fig. S1. Translations of mRNAs from rat Prdm9 mutants (red) described in Fig. 1 aligned in the SET domain with homologs from other species. G278, N320 and Y341 are amino acids essential for H3K4 trimethylation activity of PRDM9 [12, 27]. Fig. S2. Semiquantitative qRT-PCR of adult rat testicular RNAs detects no mutant mRNA degradation. The expression values were normalized with Actb primers. Primer pair "Exon 1-3" detected the KRAB-encoding exons, pair "Exon 9-10" the last SET/PR-exon plus the Zn-finger-exon. Two pairs ("20 a.a. deletion", "Intron 8") were specific for the new mRNAs of the mutant with the largest deletion (KO516-U, KO516-L, respectively), as we did not detect them in the wild-type testes (wt/wt) or in the testes hetero- or homozygous for other Prdm9 deletions (KO/wt, KO/KO). Fig. S3. Alternative views of male (a) and female (b) rat fertility parameters measured via dissections. For legend, see Figs. 2 and 3. Fig. S4. Impaired spermiation efficiency in Prdm9-deficient SHR rat. Representative images of PAS-Hstained tubular stages VIII, IX and X of Prdm9-deficient and control rats. Step 19 (S19) mature spermatids aligned near the tubule lumen for spermiation in stage VIII. However, some S19 spermatids were present beyond stage VIII in Prdm9 $9^{K O / K O}$, indicating failed spermiation - note the abnormal retention of S19 in mutant stages IX and X. Fig. S5. Spermatogenic arrests in tubular stages IV and XII of Prdm9-deficient PWD mouse. Testicular histology using PAS-H staining. Examples of tubular stages IV and XII of Prdm9-deficient and control PWD males (108 dpp). Red arrows point to degenerated spermatocytes in mutant seminiferous tubules. See Fig. 4 for abbreviations. Fig. S6. Meiotic synapsis and DSB repair in pachytene spermatocytes of adult Prdm9-deficient rats detected by immunostaining of chromosome spreads- representative images. a-f, Staining of synaptonemal complex (SYCP3), asynapsed chromosomal regions (HORMAD2), and sites under repair $(\mathrm{\gamma H} 2 \mathrm{AX})$. Completely synapsed autosomes were observed in normal cells (a-d). Sex chromosomes synapsed within the pseudo-autosomal region (a-c) became asynapsed during late pachynema (d). Aberrant spermatocytes harbored completely (e) and partially (f) asynapsed autosome pairs. g-I Labelling of SYCP1, SYCP3, and YH2AX. In normal early pachynema, all chromosomes synapsed (g-i); asynapsed $X$ and $Y$ were present at late pachynema (j). Abnormal spermatocytes carrying both autosomal and $X / Y$ asynapses $(\mathbf{k}, \mathbf{I})$ were also detected. $\mathbf{m}-\mathbf{r}$, Immunostaining for SYCP3, centromeric proteins (CENT), and early stages of DSB repair (RAD51/DMC1). In normal spermatocytes, a few RAD51/DMC1 foci were observed on autosomes and multiple foci on sex chromosomes from early pachynema (m-p). All RAD51/DMC1 signal disappeared in normal late pachynema $(\mathbf{q})$. Abnormal cells showed many 
strong RAD51/DMC1-stained foci on asynapsed chromosomes (r). Fig. S7. Correlations at hotspots in different rat strains. Hotspot strength is compared among all strains. Only autosomal hotspots that were called in both strains are considered. Each dot represents one hotspot and hotspot density is shown as a gray (low) to blue (high) gradient. The Spearman correlation coefficient (R2) is indicated for each comparison. Fig. S8. DSB hotspots are stronger on chromosome $X$ than on autosomes. Note that since there is only one copy of chromosome $\mathrm{X}$ in males, hotspot strength is scaled by a factor of two.

Additional file 2: Table S1. Genomic and CDNA sequences. Table S2. Statistics for rat PAS-H data using LRM. Table S3. Impaired spermiation efficiency (increased ESP retention) in Prdm9-deficient SHR rat. Table S4. Quantification of cells in tubular stages IV and XII of Prdm9-deficient and control PWD mice. Table S5. List of primers. Table S6. List of antibodies.

Additional file 3. Data underlying plots and graphs in figures.

\section{Acknowledgements}

We thank A. Musilová, E. Linhartová, L. Šebestová, M. Fickerová, and K. Krivivánková for technical assistance, Drs. O. Šimoník and K. Komrsková for PNA, as well as Drs. J. Forejt, B. de Massy, K. Paigen, M. Jasin, S. Keeney, J.C. Schimenti, P. Svoboda, and anonymous reviewers for comments. Some data were produced at the Microscopy Centre of the Institute of Molecular Genetics in Prague.

\section{Authors' contributions}

ZT, GVP, RDC-O, and MP conceived, planned, and supervised the project. ZT designed, VL, OM, JS, PM, and MP generated the mutant animals. OM, FP, FK, FS, TK, SG, CG, VL, PF, KT generated the data. TK, OM, FK, KB, VG, ZT performed the data analyses. TK, KB, FK, and OM designed the figures. ZT wrote the manuscript with contributions and comments from GVP, OM, FK, VG, SG, $C G, V L, K B, R D C-O, F P, T K$, and MP. All authors read and approved the final manuscript version.

\section{Funding}

This work was supported by the Czech Science Foundation (CSF, 14-20728S, 16-06548S, 19-06272S), Czech Academy of Sciences (RVO 68378050), Ministry of Education, Youth and Sports of the Czech Republic (LQ1604 NPSII, LM2015040 and LM2018126 CCP, LM2015042 CESNET, LM2015085 CERIT-SCientific Cloud, LM2015062 Czech-Biolmaging), European Regional Development Fund (CZ.1.05/1.1.00/02.0109 BIOCEV, CZ.1.05/2.1.00/19.0395, CZ.02.1.01/0.0/0.0/16_013/0001775, CZ.02.1.01/0.0/0.0/18_046/0015861), National Institute of Diabetes and Digestive and Kidney Diseases Intramural Research Program, National Institute of Health (1R01GM084104), and Myotonic Dystrophy Foundation (1-FY13-506). FK and SG were partly supported by stipends from Charles University in Prague.

\section{Availability of data and materials}

The ChIP-seq and SSDS data were submitted to the GEO database under accession number GSE163474: https://www.ncbi.nlm.nih.gov/geo/query/acc. cgi?acc=GSE163474 [76].

\section{Declarations}

\section{Ethics approval and consent to participate}

Not applicable.

\section{Competing interests}

The authors declare that they have no competing interests.

\section{Author details}

'Laboratory of Germ Cell Development, Division BIOCEV, Institute of Molecular Genetics of the Czech Academy of Sciences, 14220 Prague, Czech Republic. ${ }^{2}$ Laboratory of Genetics of Model Diseases, Institute of Physiology of the Czech Academy of Sciences, Prague, Czech Republic. ${ }^{3}$ National Institute of Diabetes, Digestive, and Kidney Diseases, National Institutes of Health, Bethesda, MD 20892, USA. ${ }^{4}$ Department of Biochemistry and Molecular Biology, Uniformed Services University of Health Sciences, Bethesda, MD 20814, USA. ${ }^{5}$ Present address: Inserm U1085 IRSET, 35042 Rennes, France. ${ }^{6}$ Institut de Génétique Humaine, CNRS UMR 9002, 34396
Montpellier, France. ${ }^{7}$ Present address: Division BIOCEV, Laboratory of Epigenetics of the Cell Nucleus, Institute of Molecular Genetics of the Czech Academy of Sciences, 14220 Prague, Czech Republic. ${ }^{8}$ Laboratory of Mouse Molecular Genetics, Division BIOCEV, Institute of Molecular Genetics of the Czech Academy of Sciences, 14220 Prague, Czech Republic.

Received: 10 September 2020 Accepted: 1 April 2021

Published online: 28 April 2021

\section{References}

1. Bolcun-Filas E, Schimenti JC: Genetics of meiosis and recombination in mice. Int Rev Cell Mol Biol. 2012;298:179-227. https://doi.org/10.1016/B9780-12-394309-5.00005-5.

2. Baudat F, Buard J, Grey C, Fledel-Alon A, Ober C, Przeworski M, Coop G, de Massy B. PRDM9 is a major determinant of meiotic recombination hotspots in humans and mice. Science. 2010;327(5967):836-40. https://doi.org/10.112 6/science.1183439.

3. Myers S, Bowden R, Tumian A, Bontrop RE, Freeman C, MacFie TS, McVean $G$, Donnelly P. Drive against hotspot motifs in primates implicates the PRDM9 gene in meiotic recombination. Science. 2010;327(5967):876-9. https://doi.org/10.1126/science.1182363.

4. Parvanov ED, Petkov PM, Paigen K. Prdm9 controls activation of mammalian recombination hotspots. Science. 2010;327(5967):835. https://doi.org/10.112 6/science.1181495.

5. Pratto F, Brick K, Khil P, Smagulova F, Petukhova GV, Camerini-Otero RD. DNA recombination. Recombination initiation maps of individual human genomes Science. 2014;346(6211):1256442. https://doi.org/10.1126/ science. 1256442

6. Flachs P, Bhattacharyya T, Mihola O, Pialek J, Forejt J, Trachtulec Z. Prdm9 incompatibility controls oligospermia and delayed fertility but no selfish transmission in mouse intersubspecific hybrids. PLoS One. 2014;9(4):e95806. https://doi.org/10.1371/journal.pone.0095806.

7. Flachs $P$, Mihola $O$, Simecek $P$, Gregorova S, Schimenti JC, Matsui Y, Baudat F, de Massy B, Pialek J, et al. Interallelic and intergenic incompatibilities of the Prdm9 (Hst1) gene in mouse hybrid sterility. PLoS Genet. 2012;8(11): e1003044. https://doi.org/10.1371/journal.pgen.1003044.

8. Mihola O, Trachtulec Z, Vlcek C, Schimenti JC, Forejt J. A mouse speciation gene encodes a meiotic histone H3 methyltransferase. Science. 2009; 323(5912):373-5. https://doi.org/10.1126/science.1163601.

9. Davies B, Hatton E, Altemose N, Hussin JG, Pratto F, Zhang G, Hinch AG, Moralli D, Biggs D, Diaz R, et al. Re-engineering the zinc fingers of PRDM9 reverses hybrid sterility in mice. Nature. 2016;530(7589):171-6. https://doi. org/10.1038/nature16931.

10. Boulton A, Myers RS, Redfield RJ. The hotspot conversion paradox and the evolution of meiotic recombination. Proc Natl Acad Sci U S A. 1997;94(15): 8058-63. https://doi.org/10.1073/pnas.94.15.8058.

11. Fairfield H, Gilbert GJ, Barter M, Corrigan RR, Curtain M, Ding Y, D'Ascenzo M, Gerhardt DJ, He C, Huang W, et al. Mutation discovery in mice by whole exome sequencing. Genome Biol. 2011;12:R86. https://doi.org/10.1186/gb-2 011-12-9-r86.

12. Hayashi $\mathrm{K}$, Yoshida $\mathrm{K}$, Matsui $\mathrm{Y}$. A histone H3 methyltransferase controls epigenetic events required for meiotic prophase. Nature. 2005;438(7066): 374-8. https://doi.org/10.1038/nature04112.

13. Weiss J, Hurley LA, Harris RM, Finlayson C, Tong M, Fisher LA, Moran JL, Beier DR, Mason C, Jameson JL. ENU mutagenesis in mice identifies candidate genes for hypogonadism. Mamm Genome. 2012;23(5-6):346-55. https://doi.org/10.1007/s00335-011-9388-5.

14. Mihola O, Pratto F, Brick K, Linhartova E, Kobets T, Flachs P, Baker CL, Sedlacek R, Paigen K, Petkov PM, Camerini-Otero RD, Trachtulec Z. Histone methyltransferase PRDM9 is not essential for meiosis in male mice. Genome Res. 2019;29(7):1078-86. https://doi.org/10.1101/gr.244426.118.

15. Brick K, Smagulova F, Khil P, Camerini-Otero RD, Petukhova GV. Genetic recombination is directed away from functional genomic elements in mice. Nature. 2012;485(7400):642-5. https://doi.org/10.1038/nature11089.

16. Baker Z, Schumer M, Haba Y, Bashkirova L, Holland C, Rosenthal GG, Przeworski M. Repeated losses of PRDM9-directed recombination despite the conservation of PRDM9 across vertebrates. Elife. 2017;6 https://doi.org/1 0.7554/eLife.24133.

17. Lam I, Keeney S. Nonparadoxical evolutionary stability of the recombination initiation landscape in yeast. Science. 2015:350(6263):932-7. https://doi.org/1 0.1126/science.aad0814. 
18. Singhal S, Leffler EM, Sannareddy K, Turner I, Venn O, Hooper DM, Strand Al, Li Q, Raney B, Balakrishnan CN, Griffith SC, McVean G, Przeworski M. Stable recombination hotspots in birds. Science. 2015;350(6263):928-32. https://doi. org/10.1126/science.aad0843.

19. Auton A, Rui Li Y, Kidd J, Oliveira K, Nadel J, Holloway JK, Hayward JJ, Cohen PE, Greally JM, Wang J, Bustamante CD, Boyko AR. Genetic recombination is targeted towards gene promoter regions in dogs. PLoS Genet. 2013;9(12): e1003984. https://doi.org/10.1371/journal.pgen.1003984.

20. Axelsson E, Webster MT, Ratnakumar A, Consortium L, Ponting CP, LindbladToh $\mathrm{K}$. Death of PRDM9 coincides with stabilization of the recombination landscape in the dog genome. Genome Res. 2012;22(1):51-63. https://doi. org/10.1101/gr.124123.111.

21. Berglund J, Quilez J, Arndt PF, Webster MT. Germline methylation patterns determine the distribution of recombination events in the dog genome. Genome Biol Evol. 2014;7(2):522-30. https://doi.org/10.1093/gbe/evu282.

22. Munoz-Fuentes V, Di Rienzo A, Vila C. Prdm9, a major determinant of meiotic recombination hotspots, is not functional in dogs and their wild relatives, wolves and coyotes. PLoS One. 2011;6(11):e25498. https://doi.org/1 0.1371/journal.pone.0025498.

23. Narasimhan VM, Hunt KA, Mason D, Baker CL, Karczewski KJ, Barnes MR, Barnett AH, Bates C, Bellary S, Bockett NA, et al. Health and population effects of rare gene knockouts in adult humans with related parents. Science. 2016;352(6284):474-7. https://doi.org/10.1126/science.aac8624.

24. Gibbs RA, Weinstock GM, Metzker ML, Muzny DM, Sodergren EJ, Scherer S, Scott G, Steffen D, Worley KC, Burch PE, et al. Genome sequence of the Brown Norway rat yields insights into mammalian evolution. Nature. 2004; 428(6982):493-521. https://doi.org/10.1038/nature02426.

25. Eram MS, Bustos SP, Lima-Fernandes E, Siarheyeva A, Senisterra G, Hajian T, Chau I, Duan S, Wu H, Dombrovski L, et al. Trimethylation of histone H3 lysine 36 by human methyltransferase PRDM9 protein. J Biol Chem. 2014; 289(17):12177-88. https://doi.org/10.1074/jbc.M113.523183.

26. Powers NR, Parvanov ED, Baker CL, Walker M, Petkov PM, Paigen K. The meiotic recombination activator PRDM9 trimethylates both $\mathrm{H} 3 \mathrm{~K} 36$ and H3K4 at recombination hotspots in vivo. PLoS Genet. 2016;12(6):e1006146. https://doi.org/10.1371/journal.pgen.1006146.

27. Wu H, Mathioudakis N, Diagouraga B, Dong A, Dombrovski L, Baudat F, Cusack S, de Massy B, Kadlec J. Molecular basis for the regulation of the H3K4 methyltransferase activity of PRDM9. Cell Rep. 2013;5(1):13-20. https:// doi.org/10.1016/j.celrep.2013.08.035.

28. Atanur SS, Birol I, Guryev V, Hirst M, Hummel O, Morrissey C, Behmoaras J, Fernandez-Suarez XM, Johnson MD, McLaren WM, et al. The genome sequence of the spontaneously hypertensive rat: analysis and functional significance. Genome Res. 2010;20(6):791-803. https://doi.org/10.1101/gr.1 03499.109.

29. Clermont $Y$. Kinetics of spermatogenesis in mammals: seminiferous epithelium cycle and spermatogonial renewal. Physiol Rev. 1972;52(1):198236. https://doi.org/10.1152/physrev.1972.52.1.198.

30. Vendramini V, Sasso-Cerri E, Miraglia SM. Amifostine reduces the seminiferous epithelium damage in doxorubicin-treated prepubertal rats without improving the fertility status. Reprod Biol Endocrinol. 2010;8(1):3. https://doi.org/10.1186/1477-7827-8-3.

31. Brilhante O, Okada FK, Sasso-Cerri E, Stumpp T, Miraglia SM. Late morfofunctional alterations of the Sertoli cell caused by doxorubicin administered to prepubertal rats. Reprod Biol Endocrinol. 2012;10(1):79. https://doi.org/10.1186/1477-7827-10-79.

32. Deng W, Lin H: miwi, a murine homolog of piwi, encodes a cytoplasmic protein essential for spermatogenesis. Dev Cell 2002,2:819-830. https://doi. org/10.1016/s1534-5807(02)00165-x,\%206.

33. Grivna ST, Pyhtila B, Lin H. MIWI associates with translational machinery and PIWI-interacting RNAs (piRNAs) in regulating spermatogenesis. Proc Natl Acad Sci U S A. 2006;103(36):13415-20. https://doi.org/10.1073/pnas. 0605506103.

34. Sun F, Fujiwara Y, Reinholdt LG, Hu J, Saxl RL, Baker CL, Petkov PM, Paigen K, Handel MA. Nuclear localization of PRDM9 and its role in meiotic chromatin modifications and homologous synapsis. Chromosoma. 2015;124: 397-415. https://doi.org/10.1007/s00412-015-0511-3.

35. Leblond CP, Clermont Y. Definition of the stages of the cycle of the seminiferous epithelium in the rat. Ann N Y Acad Sci. 1952;55:548-73. https://doi.org/10.1111/j.1749-6632.1952.tb26576.x.

36. Wojtasz L, Cloutier JM, Baumann M, Daniel K, Varga J, Fu J, Anastassiadis K, Stewart AF, Remenyi A, Turner JM, et al. Meiotic DNA double-strand breaks and chromosome asynapsis in mice are monitored by distinct HORMAD2independent and -dependent mechanisms. Genes Dev. 2012;26:958-73. https://doi.org/10.1101/gad.187559.112.

37. Liu W, Wang L, Zhao W, Song G, Xu R, Wang G, Wang F, Li W, Lian J, Tian H, Wang $X$, Sun F. Phosphorylation of CDK2 at threonine 160 regulates meiotic pachytene and diplotene progression in mice. Dev Biol. 2014;392:108-16. https://doi.org/10.1016/j.ydbio.2014.04.018.

38. Beck-Peccoz P, Persani L. Premature ovarian failure. Orphanet J Rare Dis. 2006;1:9. https://doi.org/10.1186/1750-1172-1-9.

39. Smagulova F, Brick K, Pu Y, Camerini-Otero RD, Petukhova GV. The evolutionary turnover of recombination hot spots contributes to speciation in mice. Genes Dev. 2016;30:266-80. https://doi.org/10.1101/gad.270009.115.

40. Smagulova F, Gregoretti IV, Brick K, Khil P, Camerini-Otero RD, Petukhova GV. Genome-wide analysis reveals novel molecular features of mouse recombination hotspots. Nature. 2011;472:375-8. https://doi.org/10.1038/na ture09869.

41. Dumont BL, Payseur BA. Evolution of the genomic recombination rate in murid rodents. Genetics. 2011;187(3):643-57. https://doi.org/10.1534/ genetics.110.123851.

42. Adler ID. Comparison of the duration of spermatogenesis between male rodents and humans. Mutat Res. 1996;352(1-2):169-172. https://doi.org/10.1 016/0027-5107(95)00223-5.

43. Beaumont HM, Mandl AM. Quantitative and cytological study of oogonia and oocytes in the foetal and neonatal rat. Philos Trans R Soc Lond B Biol Sci. 1962;155(961):557-59. https://doi.org/10.1098/rspb.1962.0019

44. Borum K. Oogenesis in the mouse. A study of the meiotic prophase. Exp Cell Res 1961;24(3):495-507. https://doi.org/10.1016/0014-4827(61)90449-9.

45. McClellan KA, Gosden R, Taketo T. Continuous loss of oocytes throughout meiotic prophase in the normal mouse ovary. Dev Biol. 2003;258(2):334348. https://doi.org/10.1016/s0012-1606(03)00132-5.

46. Soares JM, Avelar GF, Franca LR. The seminiferous epithelium cycle and its duration in different breeds of dog (Canis familiaris). J Anat. 2009;215(4): 462-71. https://doi.org/10.1111/j.1469-7580.2009.01122.x.

47. Andersen AC, Simpson ME. The ovary and reproductive cycle of the dog (Beagle). Theriogenology 1974;1 (1):39-42. https://doi.org/10.1016/0093-691 X(74)90062-4

48. Pravenec M, Kren V, Landa V, Mlejnek P, Musilova A, Silhavy J, Simakova M, Zidek $\mathrm{V}$. Recent progress in the genetics of spontaneously hypertensive rats. Physiol Res. 2014;63(Suppl 1):S1-8. https://doi.org/10.33549/physiolres.932 622.

49. Buard J, Barthes P, Grey C, de Massy B. Distinct histone modifications define initiation and repair of meiotic recombination in the mouse. EMBO J. 2009; 28(17):2616-24. https://doi.org/10.1038/emboj.2009.207.

50. Walker M, Billings T, Baker CL, Powers N, Tian H, Saxl RL, Choi K, Hibbs MA, Carter GW, Handel MA, Paigen K, Petkov PM. Affinity-seq detects genomewide PRDM9 binding sites and reveals the impact of prior chromatin modifications on mammalian recombination hotspot usage. Epigenetics Chromatin. 2015;8(1):31. https://doi.org/10.1186/s13072-015-0024-6.

51. Diagouraga B, Clement JAJ, Duret L, Kadlec J, de Massy B, Baudat F. PRDM9 methyltransferase activity is essential for meiotic DNA double-strand break formation at its binding sites. Mol Cell. 2018;69(5):853-65 e856. https://doi. org/10.1016/j.molcel.2018.01.033.

52. Mihola O, Trachtulec Z. A mutation of the Prdm9 mouse hybrid sterility gene carried by a transgene. Folia Biol (Praha). 2017;63(1):27-30. Available at https://fb.cuni.cz/file/5834/fb2017a0005.pdf

53. Balcova M, Faltusova B, Gergelits V, Bhattacharyya T, Mihola O, Trachtulec Z, Knopf C, Fotopulosova V, Chvatalova I, Gregorova S, Forejt J. Hybrid sterility locus on chromosome $X$ controls meiotic recombination rate in mouse. PLoS Genet. 2016;12(4):e1005906. https://doi.org/10.1371/journal.pgen.1005906.

54. Bhattacharyya T, Gregorova S, Mihola O, Anger M, Sebestova J, Denny P, Simecek P, Forejt J. Mechanistic basis of infertility of mouse intersubspecific hybrids. Proc Natl Acad Sci U S A. 2013;110(6):E468-77. https://doi.org/10.1 073/pnas.1219126110.

55. Bhattacharyya T, Reifova R, Gregorova S, Simecek P, Gergelits V, Mistrik M, Martincova I, Pialek J, Forejt J. X chromosome control of meiotic chromosome synapsis in mouse inter-subspecific hybrids. PLoS Genet. 2014; 10(2):e1004088. https://doi.org/10.1371/journal.pgen.1004088.

56. Baker CL, Kajita S, Walker M, Saxl RL, Raghupathy N, Choi K, Petkov PM, Paigen K. PRDM9 drives evolutionary erosion of hotspots in Mus musculus through haplotype-specific initiation of meiotic recombination. PLoS Genet. 2015;11(1):e1004916. https://doi.org/10.1371/journal.pgen.1004916. 
57. Baker CL, Petkova P, Walker M, Flachs P, Mihola O, Trachtulec Z, Petkov PM, Paigen K. Multimer formation explains allelic suppression of PRDM9 recombination hotspots. PLoS Genet. 2015;11(9):e1005512. https://doi.org/1 0.1371/journal.pgen.1005512.

58. Gregorova S, Gergelits V, Chvatalova I, Bhattacharyya T, Valiskova B, Fotopulosova V, Jansa P, Wiatrowska D, Forejt J. Modulation of Prdm9controlled meiotic chromosome asynapsis overrides hybrid sterility in mice. Elife. 2018;7 https://doi.org/10.7554/eLife.34282.

59. Raudsepp T, Chowdhary BP. The eutherian pseudoautosomal region. Cytogenet Genome Res. 2015;147(2-3):81-94. https://doi.org/10.1159/000443157.

60. Chen J, Cui X, Jia S, Luo D, Cao M, Zhang Y, Hu H, Huang K, Zhu Z, Hu W. Disruption of dmc1 produces abnormal sperm in medaka (Oryzias latipes). Sci Rep. 2016;6(1):30912. https://doi.org/10.1038/srep30912.

61. Oka A, Mita A, Takada Y, Koseki H, Shiroishi T. Reproductive isolation in hybrid mice due to spermatogenesis defects at three meiotic stages. Genetics. 2010;186(1):339-51. https://doi.org/10.1534/genetics.110.118976.

62. Widmayer SJ, Handel MA, Aylor DL. Age and genetic background modify hybrid male sterility in house mice. Genetics. 2020;216(2):585-97. https://doi. org/10.1534/genetics.120.303474.

63. Kusari F, Mihola O, Schimenti JC, Trachtulec Z. Meiotic epigenetic factor PRDM9 impacts sperm quality of hybrid mice. Reproduction. 2020;160(1): 53-64. https://doi.org/10.1530/REP-19-0528.

64. Mihola O, Kobets T, Krivankova K, Linhartova E, Gasic S, Schimenti JC, Trachtulec Z. Copy-number variation introduced by long transgenes compromises mouse male fertility independently of pachytene checkpoints. Chromosoma. 2020;129(1):69-82. https://doi.org/10.1007/s00412-019-00730-8.

65. Albrechtova J, Albrecht T, Dureje L, Pallazola VA, Pialek J. Sperm morphology in two house mouse subspecies: do wild-derived strains and wild mice tell the same story? PLoS One. 2014;9(12):e115669. https://doi. org/10.1371/journal.pone.0115669.

66. Turner LM, Harr B. Genome-wide mapping in a house mouse hybrid zone reveals hybrid sterility loci and Dobzhansky-Muller interactions. Elife. 2014;3 https://doi.org/10.7554/eLife.02504.

67. Pravenec M, Kurtz TW. Recent advances in genetics of the spontaneously hypertensive rat. Curr Hypertens Rep. 2010;12(1):5-9. https://doi.org/10.1 007/s11906-009-0083-9.

68. Ivics Z, Mates L, Yau TY, Landa V, Zidek V, Bashir S, Hoffmann OI, Hiripi L, Garrels W, Kues WA, et al. Germline transgenesis in rodents by pronuclear microinjection of sleeping beauty transposons. Nat Protoc. 2014;9(4):773-93. https://doi.org/10.1038/nprot.2014.008.

69. Anderson LK, Reeves A, Webb LM, Ashley T. Distribution of crossing over on mouse synaptonemal complexes using immunofluorescent localization of MLH1 protein. Genetics. 1999;151(4):1569-79. Available at https://www.ncbi. nlm.nih.gov/pmc/articles/PMC1460565/pdf/10101178.pdf

70. Grey C, Clement JA, Buard J, Leblanc B, Gut I, Gut M, Duret L, de Massy B. In vivo binding of PRDM9 reveals interactions with noncanonical genomic sites. Genome Res. 2017;27(4):580-90. https://doi.org/10.1101/gr.217240.116.

71. Bankhead P, Loughrey MB, Fernandez JA, Dombrowski Y, McArt DG, Dunne PD, McQuaid S, Gray RT, Murray LJ, Coleman HG, et al. QuPath: open source software for digital pathology image analysis. Sci Rep. 2017;7(1):16878. https://doi.org/10.1038/s41598-017-17204-5.

72. Brick K, Pratto F, Sun CY, Camerini-Otero RD, Petukhova G. Analysis of meiotic double-strand break initiation in mammals. Methods Enzymol. 2018; 601:391-418 https://doi.org/10.1016/bs.mie.2017.11.037.

73. Khil PP, Smagulova F, Brick KM, Camerini-Otero RD, Petukhova GV. Sensitive mapping of recombination hotspots using sequencing-based detection of ssDNA. Genome Res. 2012;22(5):957-65. https://doi.org/10.1101/gr.130583.111.

74. Kuhn RM, Haussler D, Kent WJ. The UCSC genome browser and associated tools. Brief Bioinform. 2013;14(2):144-61. https://doi.org/10.1093/bib/bbs038.

75. Durinck S, Spellman PT, Birney E, Huber W. Mapping identifiers for the integration of genomic datasets with the R/bioconductor package biomaRt. Nat Protoc. 2009;4(8):1184-91. https://doi.org/10.1038/nprot.2009.97.

76. Mihola O, Landa V, Pratto F, Brick K, Smagulova F, Kobets T, Flachs P, Gergelits V, Tresnak K, Silhavy J, Mlejnek P, Camerini-Otero RD, Pravenec M, Galina P, Trachtulec Z. Rat PRDM9 shapes recombination landscapes, duration of meiosis, gametogenesis, and age of fertility. NCBI GEO https:// identifiers.org/ncbi/geo:GSE163474. Accessed on 10 Apr 2021.

\section{Publisher's Note}

Springer Nature remains neutral with regard to jurisdictional claims in published maps and institutional affiliations.

Ready to submit your research? Choose BMC and benefit from:

- fast, convenient online submission

- thorough peer review by experienced researchers in your field

- rapid publication on acceptance

- support for research data, including large and complex data types

- gold Open Access which fosters wider collaboration and increased citations

- maximum visibility for your research: over $100 \mathrm{M}$ website views per year

At BMC, research is always in progress.

Learn more biomedcentral.com/submissions 